\title{
MARCAÇÃO DE FOCO ESTREITO E O ACENTO SECUNDÁRIO EM INTERROGATIVAS TOTAIS NO PORTUGUÊS DO BRASIL
}

\author{
PRODUCTION OF NARROW FOCUS AND THE SECONDARY STRESS \\ IN BRAZILIAN PORTUGUESE YES/NO QUESTIONS
}

\author{
Manuella Carnaval | Lattes | manuellacarnaval@gmail.com \\ Universidade Federal do Rio de Janeiro \\ João Antonio de Moraes | Lattes | jamoraes3@gmail.com \\ Universidade Federal do Rio de Janeiro
}

Albert Olivier Blaise Rilliard | Lattes | albert.rilliard@limsi.fr Universidade Federal do Rio de Janeiro

Resumo: Este artigo tem como principal objetivo investigar, em enunciados interrogativos totais, a relação entre a marcação prosódica do foco estreito e o acento secundário, no Português do Brasil, do ponto de vista da percepção e da produção. Foi elaborado um corpus de fala atuada, composto por 21 enunciados, para esta finalidade, de modo que fossem contempladas palavras focalizadas com variação do número de sílabas pretônicas, apresentando condições favoráveis e não favoráveis à ocorrência do acento secundário. Essas palavras apresentaram distribuição pelos seguintes contextos prosódicos: vocábulo final do enunciado, coincidindo com cabeça de I; vocábulo cabeça de sintagma fonológico $(\phi)$, posição mais forte; vocábulo que não constitui cabeça de $\phi$, situando-se em posição fraca, à esquerda, podendo o sintagma fonológico estar ao início, meio ou final do enunciado. Esses enunciados foram submetidos a um teste perceptivo, com 20 juízes, que apontou para altas taxas de reconhecimento do foco interrogativo em todos os contextos analisados. Nossa análise permitiu identificar as seguintes estratégias de focalização: a associação de um pico geminado à posição do acento secundário na palavra focalizada; a compressão temporal do pico geminado, em palavras com apenas uma pretônica, portanto, que não apresentam condições favoráveis à ocorrência do acento secundário; o alongamento da sílaba tônica da palavra focalizada.

Palavras-chave: Entoação; Foco; Interrogação; Acento secundário; Fonologia prosódica. 
Abstract: This paper investigates the relation, in perception and production, between prosodic marking of narrow focus and secondary stress in yes-no questions in Brazilian Portuguese. A 21-utterance corpus was built, presenting systematic variations in the focalized words, in terms of position of focus in the utterance, and number of pre-tonic syllables (linked to the presence of a secondary stress). The focused word appears at the following prosodic contexts: at the end of utterance, as head of the intonation phrase, or at a strong position as head of phonological phrase $(\phi)$, or at a weak position in $\phi$. The phonological phrase may be found at the beginning, middle or final part of utterance. Stimuli were evaluated by 20 listeners for the localization of the narrow focus, with high recognition scores for all the contexts analysed. Acoustic descriptions support a description of narrow focus performed with a geminate intonation peak related to a secondary stress on the focused word, and a temporal compression of the geminated peak in words presenting just one pretonic syllable, that is, without favourable conditions for secondary stress; a significant lengthening of segmental duration was observed in the stressed syllable of the focused word.

Keywords: Intonation; Focus; Yes-no questions; Secondary stress; Prosodic phonology.

\section{Introdução}

A interação comunicativa exige do interlocutor o entendimento de uma proposição emitida pelo falante e esta compreensão tem como "ponto de partida" uma informação conhecida previamente pelos dois participantes da situação de comunicação, falante e ouvinte, e segue em direção ao que se constitui como informação nova, noção que remonta a Weil (1844 apud MITTMANN, 2012, p. 134). O enunciado é, então, caracterizado como uma estrutura bipartida e os conceitos de fundo (f) e foco (F) (VALLDUVÍ, 1992, 2003; HANN, 2002; KRUIJFFKORBAYOVÁ; STEEDMAN, 2003) abordam, respectivamente, a sua composição informacional em termos de porção não informativa (ou menos informativa) e informativa:

(1) A: Quando o porteiro recebeu a correspondência? B: $[\text { O porteiro recebeu a correspondência }]_{\mathrm{f}}[\text { ontem }]_{\mathrm{F}}$.

A partir do ilustrado no exemplo (1), podemos entender a focalização como um processo em que a porção do enunciado que corresponde à informação nova é requisitada por uma pergunta anterior (MORAES, 2006). Em enunciados interrogativos totais, a informação nova, que constitui seu foco, não é mais fornecida pelo falante, como na asserção, mas sim por ele solicitada (MORAES; CARNAVAL; COELHO, 2015), como podermos verificar na troca abaixo: 
(2) A: O porteiro recebeu a correspondência.

$\mathrm{B}$ : $[\mathrm{O} \text { porteiro recebeu a correspondência }]_{\mathrm{f}}[\text { ontem }]_{\mathrm{F}}$ ?

Assim, o foco recai sobre uma parte da pergunta.

Com relação à extensão do termo focalizado, é consensual, na literatura especializada, a denominação de dois tipos de foco: foco amplo e foco estreito (FROTA, 2000; AVESANI; VAYRA, 2003; SITYAEV; HOUSE, 2003; LADD, 2008; MORAES; CARNAVAL; COELHO, 2015; CARNAVAL, 2017). Essa categorização foi definida em Moraes, Carnaval e Coelho (2015) como uma "dimensão contínua”, construída a partir do aumento gradual da extensão do constituinte focalizado, o que será detalhado na seção seguinte. Nesse trabalho, os autores, ao abordarem a marcação prosódica do foco em enunciados interrogativos totais, puderam observar que, nos casos de foco estreito (mais especificamente, recaindo sobre palavra fonológica), uma subida melódica suplementar com uma distância mínima de duas sílabas da tônica foi utilizada como estratégia pelos informantes do corpus para destacar a palavra em foco de alguns dos enunciados analisados. Essa dupla modulação melódica sobre o vocábulo sob foco estreito foi, então, associada à posição do acento secundário da palavra focalizada, tendo em vista que o acento secundário ocorre dentro do limite da palavra fonológica (LEE, 2002; MORAES, 2003a), desde que apresente a condição mínima de duas sílabas pretônicas para ser manifestado.

Sendo este um achado que nos surpreendeu na análise, procura-se no presente estudo aprofundar, com um corpus expressamente elaborado para esse fim, a investigação da marcação do foco estreito a partir da associação de um pico geminado à posição do acento secundário das palavras focalizadas em enunciados interrogativos totais. Nosso especial interesse nesse tipo de enunciado se deve ao reduzido número de trabalhos que investigam a realização prosódica do foco em enunciados interrogativos, bem como por ter sido verificado em trabalho anterior (MORAES; CARNAVAL; COELHO, 2015), sobre o foco prosódico em interrogativas totais, a relação entre a produção focal e o acento secundário.

Assim, os objetivos definidos neste estudo são:

- Averiguar o peso / a eficácia da manifestação do acento secundário na marcação do foco estreito.

- Verificar as alternativas possíveis para a marcação do foco estreito quando a realização do acento secundário é inibida (menos de 2 sílabas pretônicas). 


\section{0 acento secundário no PB}

Em relação ao Português do Brasil, o acento secundário tem sido tratado em diversos trabalhos, seja de uma perspectiva fonológica, como em Bisol (1992, 1994), Collischonn (1993, 1994), Lee (2002), Sandalo et al.(2006), Fernandes-Svartman et al.(2009); seja enfatizando sua manifestação fonética, como em Arantes (2010), Arantes e Barbosa (2002, 2008), Fernandes-Svartman et al.(2012), Moraes (2003a, 2003b), Rossi (1998).

Para Lee (2002), o acento secundário difere do acento primário por ser insensível à quantidade de peso silábico e à categoria lexical, sendo puramente fonológico. Assim, o acento primário tem sua aplicação no nível lexical, enquanto o acento secundário no $\mathrm{PB}$ possui caráter iterativo, ocorrendo regularmente a cada 2 sílabas, da direita para a esquerda, a partir do acento primário, sempre dentro do domínio da palavra fonológica $(\omega)$, como pode ser verificado nos exemplos abaixo, em que a sílaba em negrito apresenta o acento secundário e as sílabas entre parênteses o acento primário:
a. $\quad \operatorname{Deses}(\mathrm{pe})$ ro
b. $\quad$ Desespera $(\text { dor })^{1}$
c. Desespe(ra)do ou Desespe(ra)do

No último exemplo (c), podem ser observados dois padrões de atribuição do acento secundário. Lee (2002) e Moraes (2003a) destacam a possibilidade de alternância de padrões quando o número de pretônicas é ímpar, ocorrendo o efeito dactílico ou pé troqueu no início da palavra, com o deslocamento do acento secundário para a primeira sílaba.

Moraes (2003, p. 148), a partir de uma abordagem acústica do fenômeno, define o acento secundário como "a proeminência que vai incidir sobre determinadas sílabas de palavra, marcando assim as fronteiras do pé”, sendo, portanto, a marca formal do pé métrico. Para o autor, o acento secundário é um fenômeno fonético-fonológico no PB, que se manifesta nas palavras com mais de uma sílaba pretônica. Dentre os parâmetros analisados, o estudo destaca a atuação da F0 na marcação acústica do acento secundário juntamente com a da duração. Esse dado direciona em nossa análise a observância de tais fatores para avaliar a relevância do acento secundário na marcação do foco estreito em enunciados interrogativos totais no PB.

\footnotetext{
${ }^{1}$ Na realidade, o padrão (b), com dois acentos secundários, previsto em estudos de cunho fonológico, como Lee (2002), costuma se realizar, em contextos não enfáticos, com um dos acentos secundários previstos apenas.
} 


\section{$3 \mathbf{O}$ pico geminado como correlato do foco interrogativo}

Em Moraes, Carnaval e Coelho (2015), procurou-se averiguar a marcação do foco em enunciados interrogativos totais a partir de diferentes extensões, indo do domínio mais estreito (palavra fonológica) para o mais amplo (enunciado completo), na mesma frase: “O marido da Renata derrubou suco de laranja?”, como esquematizado na Figura 1.

Figura 1. Contínuo de domínios prosódicos que podem estar sob foco, indo do foco mais estreito para o mais amplo, no enunciado "O marido da Renata derrubou suco de laranja".

$\begin{aligned} & \text { FOCO } \\ & + \text { ESTREITO }\end{aligned}$
$\begin{aligned} & \text { FOCO } \\ & \text { Palavra fonológica }(\omega)\end{aligned}$
$\begin{aligned} & \text { DE LARANJA } \\ & \text { SUCO }\end{aligned}$
$\begin{aligned} & \text { DERRUBOU } \\ & \text { O MARIDO }\end{aligned}$
$\begin{aligned} & \text { DA RENATA } \\ & \text { DAMPLO }\end{aligned}$

Verificou-se que o foco amplo² é caracterizado por uma dupla subida melódica, nas posições pré-nuclear, primeira sílaba tônica do enunciado, e nuclear, última sílaba tônica do enunciado, como indicado na Figura 2.

Figura 2. Contorno melódico da frase interrogativa $O$ marido da Renata derrubou suco de laranja? dita com foco amplo, pelo informante C. (MORAES; CARNAVAL; COELHO, 2015).

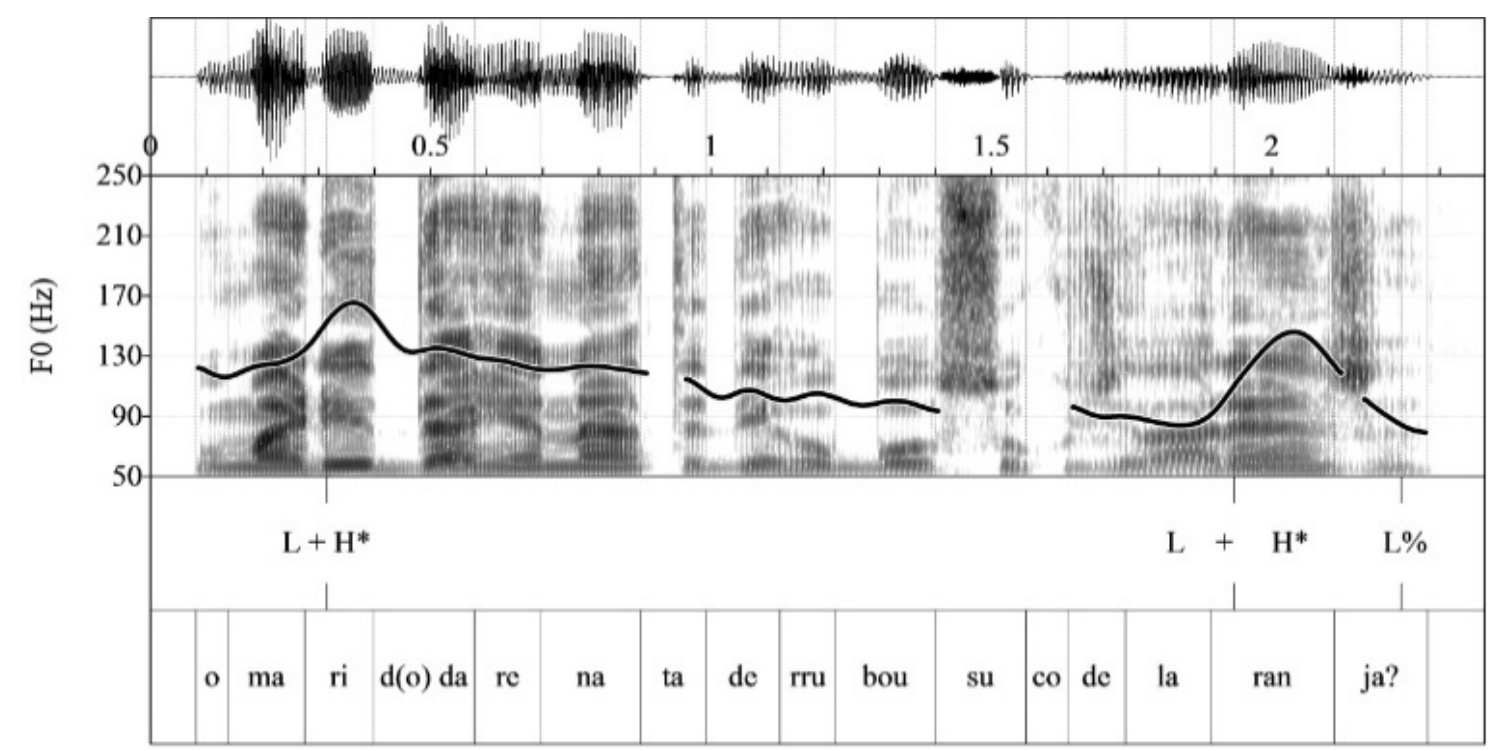

\footnotetext{
${ }^{2}$ Entende-se por foco amplo a ausência de foco sobre um constituinte específico.
} 
Com relação ao foco estreito, quando o foco recai sobre palavra fonológica, este pode ser marcado pelo que foi, então, por nós nomeado "pico geminado", associado à posição do acento secundário sobre a palavra focalizada, ao qual foi atribuído o tom complexo HLH* , como pode ser observado na Figura 3. Assim, além das inflexões ascendentes no pré-núcleo e no núcleo, há, ainda, uma terceira proeminência melódica, sobre a palavra focalizada, caracterizada pelo pico geminado, cuja realização fonética ocorre em associação à posição de um possível acento secundário, em sílaba pretônica não adjacente à tônica.

Figura 3. Contorno melódico da frase $O$ marido DA RENATA derrubou suco de laranja?, dita com foco sobre da Renata, pelo informante A; presença do pico geminado assinalada pelo retângulo em vermelho (MORAES; CARNAVAL; COELHO, 2015).

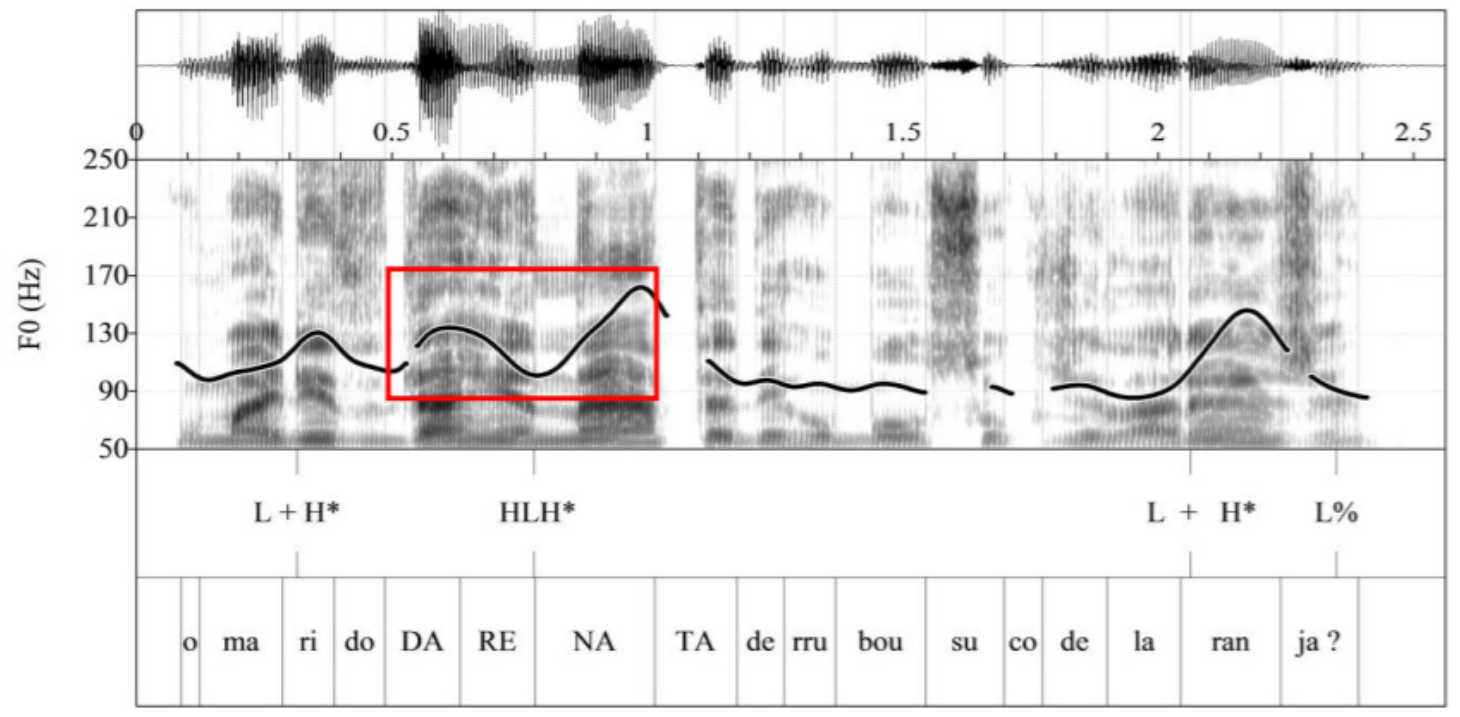

Quando a palavra focalizada ocupa a posição final do sintagma entonacional, (I) (Figura 4), a presença do pico geminado na posição final torna-se especialmente relevante para distinguir foco amplo de foco estreito, uma vez que já não há a possibilidade de uma subida melódica extra (a terceira) assinalar o vocábulo em foco, como ocorre nos demais casos, justamente pelo fato de o constituinte focalizado se situar na posição final do enunciado, que já deve receber uma subida por default. Assim, se entre esses dois tipos de foco é percebida uma diferença, esta será devida à presença de algum correlato especial, como o pico geminado associado ao acento secundário e/ou um comportamento diferenciado da duração, por exemplo. 
Figura 4. Contorno melódico da frase O marido da Renata derrubou suco DE LARANJA?, dita com foco sobre laranja, pelo informante A; presença do pico geminado assinalada pelo retângulo em vermelho (MORAES; CARNAVAL; COELHO, 2015).

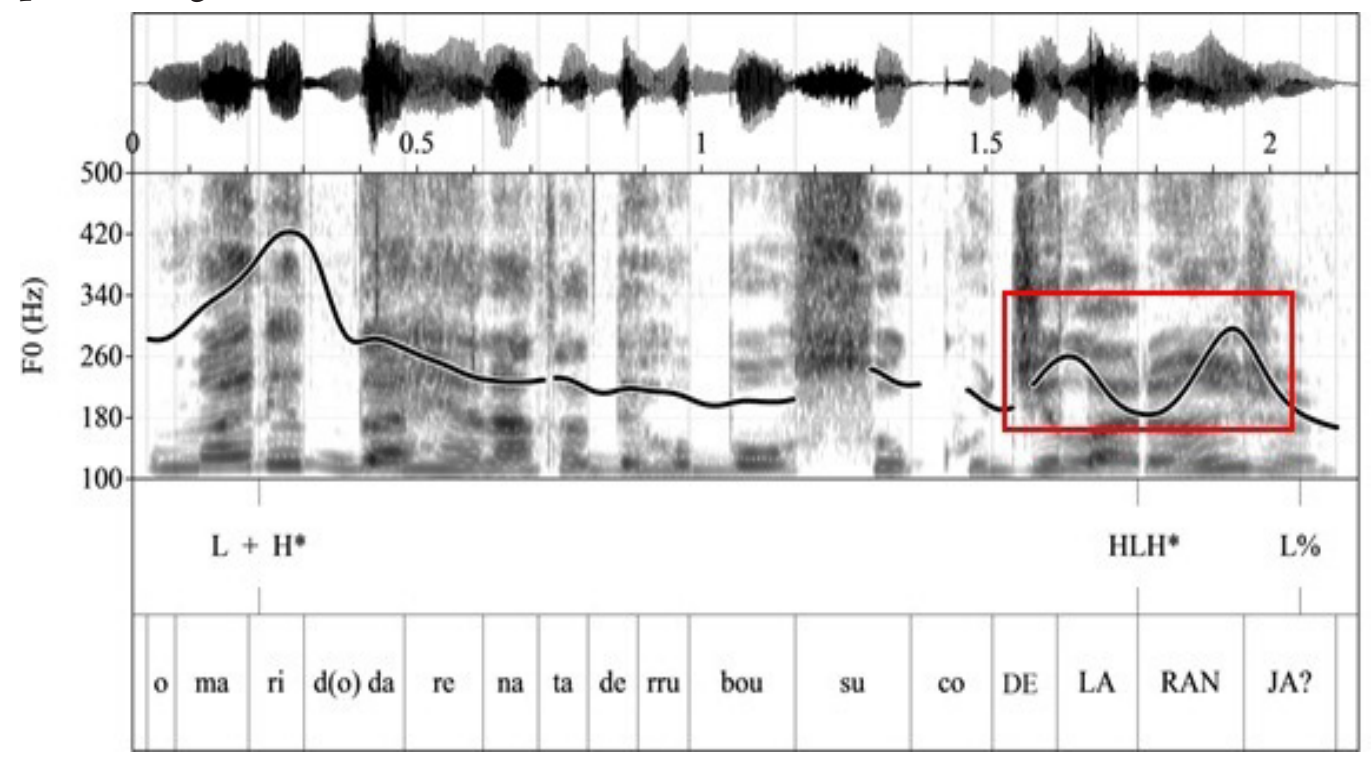

Partindo de nossas indagações específicas sobre a importância do acento secundário na marcação prosódica do foco estreito em interrogativas totais no $\mathrm{PB}$, as hipóteses que pretendemos averiguar são:

Possui o acento secundário um papel legítimo na marcação do foco estreito, sendo caracterizado fonologicamente por um pico geminado no contorno melódico sobre o constituinte focalizado?

Quando sua manifestação é inibida (menos de duas sílabas pretônicas), a distinção entre foco estreito e amplo nas interrogações é neutralizada? Ou, ao contrário, o foco estreito pode ser compensatoriamente marcado pela manifestação de outros parâmetros, como o aumento da duração sobre o foco ou, até mesmo, pelo deslocamento do tom alto do acento secundário para a primeira pretônica, na eventualidade de haver uma pretônica, caracterizando um ajuste melódico ao material textual (FROTA et al., 2015)?

\section{Metodologia}

\subsection{0 corpus}

Foi elaborado um corpus de fala não espontânea, controlada, composto pelas seguintes frases: 


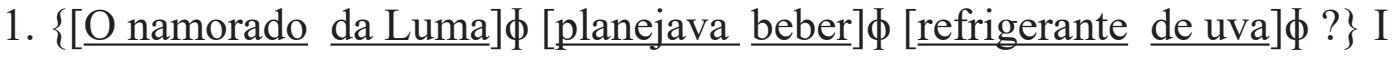
$\omega$
$\omega$
$\omega$
$\omega$
$\omega$
$\omega$

2. $\{[\underline{\text { O primo da Manuela }}] \phi$ [vai derrubar $] \phi$ [ $\underline{\text { suco de tangerina }}] \phi$ ? $\}$ I
$\omega$
$\omega$
$\omega \omega$
$\omega$
$\omega$

3. $\{[$ Festa cheia $] \phi[$ costuma dar $] \phi[$ refresco quente $] \phi ?\}$ I
$\omega \omega$
$\omega$
$\omega$
$\omega$
$\omega$

Atentando para os domínios hierárquicos prosódicos constitutivos do enunciado (NESPOR;VOGEL, 1986), procurou-se estabelecer uma composição simétrica em cada estrutura textual, de modo que consistissem em um sintagma entonacional (I) formado por três sintagmas fonológicos $(\phi)$. Estes, por sua vez, são compostos, cada um, por duas palavras fonológicas ( $\omega$ ), domínio do acento secundário (LEE, 2002), uma ocupando a posição forte, cabeça de $\phi$, e outra a posição fraca, à esquerda. Pronunciadas com foco amplo (toda a frase) e foco estreito (sobre cada uma das palavras fonológicas que integram as frases), foram gerados 21 enunciados, gravados por 2 informantes (masculino e feminino, falantes da variedade do Rio de Janeiro) perfazendo um total de 42 enunciados. Esses 21 enunciados são apresentados no Quadro 1.

Quadro 1. Estímulos sonoros produzidos por cada informante a partir de cada frase, com foco amplo na primeira linha e foco estreito (em negrito) nas demais.

\begin{tabular}{|l|l|l|}
\hline \multicolumn{1}{|c|}{ Frase 1 } & \multicolumn{1}{|c|}{ Frase 2 } & \multicolumn{1}{c|}{ Frase 3 } \\
\hline $\begin{array}{l}\text { O namorado da Luma planeja- } \\
\text { va beber refrigerante de uva? }\end{array}$ & $\begin{array}{l}\text { O primo da Manuela vai derrubar } \\
\text { suco de tangerina? }\end{array}$ & $\begin{array}{l}\text { Festa cheia costuma dar } \\
\text { refresco quente? }\end{array}$ \\
\hline $\begin{array}{l}\text { O namorado da Luma plane- } \\
\text { java beber refrigerante de uva? }\end{array}$ & $\begin{array}{l}\text { O primo da Manuela vai derru- } \\
\text { bar suco de tangerina? }\end{array}$ & $\begin{array}{l}\text { Festa cheia costuma dar } \\
\text { refresco quente? }\end{array}$ \\
\hline $\begin{array}{l}\text { O namorado da Luma plane- } \\
\text { java beber refrigerante de uva? }\end{array}$ & $\begin{array}{l}\text { O primo da Manuela vai derru- } \\
\text { bar suco de tangerina? }\end{array}$ & $\begin{array}{l}\text { Festa cheia costuma dar } \\
\text { refresco quente? }\end{array}$ \\
\hline $\begin{array}{l}\text { O namorado da Luma plane- } \\
\text { java beber refrigerante de uva? }\end{array}$ & $\begin{array}{l}\text { O primo da Manuela vai derru- } \\
\text { bar suco de tangerina? }\end{array}$ & $\begin{array}{l}\text { Festa cheia costuma dar } \\
\text { refresco quente? }\end{array}$ \\
\hline $\begin{array}{l}\text { O namorado da Luma planeja- } \\
\text { va beber refrigerante de uva? }\end{array}$ & $\begin{array}{l}\text { O primo da Manuela vai derru- } \\
\text { bar suco de tangerina? }\end{array}$ & $\begin{array}{l}\text { Festa cheia costuma dar } \\
\text { refresco quente? }\end{array}$ \\
\hline $\begin{array}{l}\text { O namorado da Luma planeja- } \\
\text { va beber refrigerante de uva? }\end{array}$ & $\begin{array}{l}\text { O primo da Manuela vai derrubar } \\
\text { suco de tangerina? }\end{array}$ & $\begin{array}{l}\text { Festa cheia costuma dar re- } \\
\text { fresco quente? }\end{array}$ \\
\hline $\begin{array}{l}\text { O namorado da Luma planeja- } \\
\text { va beber refrigerante de uva? }\end{array}$ & $\begin{array}{l}\text { O primo da Manuela vai derrubar } \\
\text { suco de tangerina? }\end{array}$ & $\begin{array}{l}\text { Festa cheia costuma dar } \\
\text { refresco quente? }\end{array}$ \\
\hline
\end{tabular}


Para a obtenção destes enunciados interrogativos ditos com diferentes focos, foram criados pequenos contextos. ${ }^{3}$ Após a leitura desses contextos, os informantes produziram os diferentes enunciados apresentados acima. No corpus, opusemos as palavras dos enunciados a partir da quantidade de sílabas pretônicas, em cada contexto de análise, como esquematizado no Quadro 2.

Quadro 2. Palavras que compõem nosso corpus apresentadas segundo seus contextos estruturais e o número de pretônicas apresentado por cada uma.

\begin{tabular}{|c|c|c|c|c|}
\hline \multicolumn{2}{|c|}{$\mathrm{N}_{\text {Contextos }}^{\mathrm{N}^{\circ} \text { de pretônicas }}$} & 2 ou mais pretônicas & 1 pretônica & Sem pretônica \\
\hline \multicolumn{2}{|c|}{$\begin{array}{l}\text { Vocábulo cabeça do } \\
\text { sintagma entonacional (I) }\end{array}$} & $\begin{array}{l}\text { de tangerina } \\
321 \mathrm{~T}\end{array}$ & $\begin{array}{l}\text { de uva } \\
1 \mathrm{~T}\end{array}$ & $\begin{array}{l}\text { quente } \\
\mathrm{T}\end{array}$ \\
\hline \multicolumn{2}{|l|}{$\begin{array}{l}\text { Posição forte } \\
\text { (cabeça de } \phi)\end{array}$} & $\begin{array}{l}\text { derrubar } \\
21 \mathrm{~T} \\
\text { da Manuela } \\
321 \mathrm{~T}\end{array}$ & $\begin{array}{l}\text { beber } \\
1 \mathrm{~T} \\
\text { da Luma } \\
1 \mathrm{~T}\end{array}$ & $\begin{array}{l}\text { dar } \\
T \\
\text { cheia } \\
T\end{array}$ \\
\hline \multirow{3}{*}{$\begin{array}{l}\text { Posição fraca (à } \\
\text { esquerda de } \phi)\end{array}$} & $\phi$ final & $\begin{array}{l}\text { refrigerante } \\
321 \mathrm{~T}\end{array}$ & $\begin{array}{l}\text { refresco } \\
1 \mathrm{~T}\end{array}$ & $\underset{T}{\operatorname{suco}}$ \\
\hline & $\begin{array}{l}\phi \\
\text { medial }\end{array}$ & $\begin{array}{l}\text { planejava } \\
21 \mathrm{~T}\end{array}$ & $\begin{array}{l}\text { costuma } \\
1 \mathrm{~T}\end{array}$ & $\begin{array}{l}\text { vai } \\
T\end{array}$ \\
\hline & $\underset{\text { inicial }}{\phi}$ & $\begin{array}{l}\text { O namorado } \\
321 \mathrm{~T}\end{array}$ & $\begin{array}{l}\text { O primo } \\
1 \mathrm{~T}\end{array}$ & $\begin{array}{l}\text { Festa } \\
T\end{array}$ \\
\hline
\end{tabular}

Objetivando dar continuidade à análise realizada em Moraes, Carnaval e Coelho (2015), os contextos de análise dos padrões melódicos com foco estreito foram mantidos, a saber: vocábulo final do enunciado, coincidindo com cabeça de I; vocábulo cabeça de sintagma fonológico $(\phi)$, posição mais forte; vocábulo que não constitui cabeça de $\phi$, situando-se em posição mais fraca, à esquerda. No último contexto, consideramos, ainda, três possibilidades a partir da posição do sintagma fonológico $(\phi)$, ao início, meio ou final do enunciado.

O controle do número de sílabas pretônicas no domínio da palavra fonológica $(\omega)$ pretendeu propiciar, com a condição mínima de duas sílabas pretônicas, ou inibir, sem respeitar esta restrição, a manifestação do acento secundário. No segundo caso, foram consideradas duas possibilidades: (i) palavra com uma única sílaba pretônica, para averiguar o possível deslocamento do tom alto do acento secundário para a pretônica existente, e (ii) palavra sem sílabas pretônicas, onde o citado deslocamento não seria uma opção.

\footnotetext{
${ }^{3}$ Contextos similares a esses podem ser vistos em Moraes, Carnaval e Coelho (2015, p. 173-174).
} 


\subsection{Teste de percepção}

Os 42 enunciados do corpus foram utilizados na aplicação de um teste perceptivo de escolha forçada, realizado com 20 juízes, para validar auditivamente a marcação do foco estreito e avaliar a qualidade dos dados obtidos, compensando-se assim o tamanho relativamente reduzido do corpus. Esse teste foi dividido em 3 etapas, relativas aos enunciados produzidos a partir de cada uma das 3 frases. Em cada etapa, os enunciados foram dispostos de forma aleatória para os voluntários, que, após ouvi-los, deveriam selecionar dentre as sete opções disponibilizadas aquela que seria o foco da pergunta. Além das opções de foco estreito, sobre cada uma das seis palavras fonológicas que compõem os enunciados, o ouvinte poderia, ainda, selecionar a opção "sem foco", relativa ao foco amplo, quando não identificasse foco sobre um constituinte específico.

\subsection{Análise acústica}

Nossa análise contempla a descrição fonética dos padrões de focalização em questão, além da atribuição de uma notação fonológica em pontos relevantes dos contornos melódicos analisados, a partir do modelo AM/ToBI (JUN, 2005, 2014), com alguma adaptação ${ }^{4}$. Os padrões prosódicos foram obtidos com o programa Praat de análise acústica, com o qual foram obtidas também as medidas de duração aqui consideradas.

\subsubsection{Padrões melódicos}

Além das figuras que ilustram visualmente o comportamento melódico da focalização, procurou-se dar uma descrição qualitativa da evolução da F0 ao longo dos enunciados, procurando, assim, apontar as estratégias e os padrões de focalização encontrados nas distintas posições em que o foco figurava no enunciado.

\subsubsection{Duração}

Com o programa de análise acústica Praat, os enunciados de nosso corpus foram segmentados por sílaba, cuja duração, medida em segundos, foi descrita aqui de maneira a contemplar as partes dos enunciados que têm maior ou menor alongamento de sílaba, sob efeito da focalização das palavras e de outros fatores que poderiam ter influência sobre o aumento de duração. As três frases que compõem nosso corpus foram construídas de maneira a apresentar características equilibradas do ponto de vista fonológico e sintático (cf. Seção 4.1), mas apresentam, inevitavelmente, variações na natureza dos fonemas que compõem cada sílaba. Essa característica pode, assim, interferir na duração intrínseca

\footnotetext{
${ }^{4}$ Especialmente a atribuição do tom complexo $\mathrm{HLH}^{*}$ ao pico geminado.
} 
das sílabas (BARBOSA, 2007). Devido a essas considerações, o alongamento das sílabas de cada frase com foco estreito foi medido em relação à mesma sílaba na frase equivalente com foco amplo, isto é, na ausência de foco sob uma palavra específica, seguindo a equação em 1.

$$
\text { (4) } \delta=\log _{10}\left(\frac{d_{e}}{d_{a}}\right)
$$

Nesta equação, o alongamento é medido como o logaritmo de base 10 da razão entre a duração da sílaba da frase com foco estreito $\left(d_{\mathrm{e}}\right)$ e a duração da sílaba correspondente na frase com foco amplo (ver BELIÃO, 2016, para uma abordagem comparável do alongamento, por exemplo). A utilização desse logaritmo garante que a razão seja simétrica. Segundo esse cálculo, para o caso de não haver alongamento, com a medida igual a 0 , a duração da sílaba nas duas frases deve ser idêntica; uma medida de 0,3 corresponderia aproximadamente a uma duração duas vezes maior da mesma sílaba com foco estreito em relação à sílaba com foco amplo $\left(\mathrm{d}_{\mathrm{a}}\right)$ (respectivamente, uma medida de -0,3 indicaria uma duração para o foco estreito que corresponderia aproximadamente à metade da duração do foco amplo). A medida foi aferida sobre cada sílaba das frases, seja uma sílaba tônica, postônica ou pretônica. A posição da palavra fonológica $(\omega)$ que contém a sílaba analisada, dentro da frase, constitui outro fator de variação do alongamento, sendo identificada de 1 (primeira palavra fonológica) até 6 (última palavra fonológica das frases).

\section{Resultados}

\subsection{Teste perceptivo}

A Figura 5 ilustra os percentuais de reconhecimento do foco amplo e do foco estreito em cada contexto de ocorrência por quantidade de sílabas pretônicas apresentada. Podemos observar que todos os índices apresentados na Figura 5 são muito superiores à taxa de acerto ao acaso (14\% - pois os ouvintes deviam optar por uma resposta dentre 7 disponíveis).

Para que uma análise estatística pudesse ser realizada sobre os resultados do teste perceptivo aplicado, as respostas dos juízes foram codificadas em termos de acerto e erro. Desse modo, a taxa média de acerto referente à categorização segundo a "posição" do foco (agrupando as respostas referentes aos 3 enunciados que compõem nosso corpus) foi utilizada como variável dependente em uma regressão logística, com os seguintes fatores: posição do foco no enunciado ( 6 níveis: foco amplo, cabeça de I, cabeça de $\phi$, esquerda de $\phi$ inicial, esquerda de $\phi$ medial, esquerda de $\phi$ final); número de sílabas pretônicas (3 níveis: sem pretônica, uma pretônica, duas ou mais pretônicas); interação entre os dois fatores precedentes (ver Figura 5 para mais detalhes). 
Figura 5. Taxa de reconhecimento dos constituintes focalizados; no eixo vertical, a porcentagem de identificações corretas, no horizontal, os contextos analisados apresentados de acordo com o número de pretônicas da palavra.

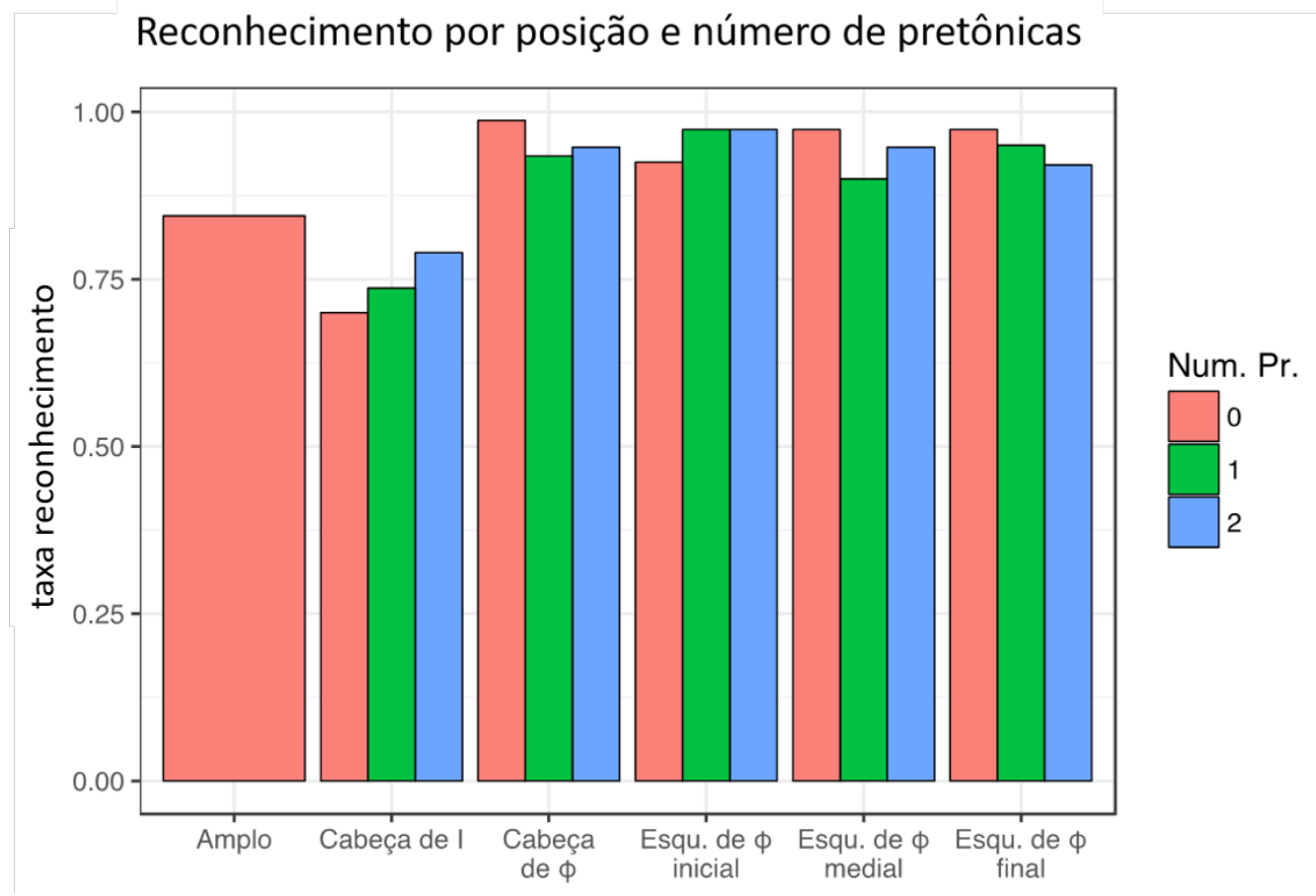

Um processo de simplificação de modelo (CRAWLEY, 2013), para a exclusão de fatores não significativos, mostrou que a interação $\left(\mathrm{LRT}^{5}=8.0\right.$, d.f. $\left.=8, \mathrm{p}=0.43\right)$ e o número de sílabas pretônicas $(\mathrm{LRT}=0.7$, d.f. $=2, \mathrm{p}=0.70)$ não apresentam um efeito significativo sobre a taxa de acerto. Na verdade, o modelo ótimo explica a variação da taxa de categorização correta do foco em função de sua posição nos enunciados (LRT = 48.2, d.f. $=5, \mathrm{p}<0.001)$. Este fator apresentou, na simplificação do modelo, o agrupamento de níveis similares (cf. Figura 5). As posições foco amplo e foco sobre cabeça de I foram agrupados em um novo nível, constituindo um modelo equivalente ao precedente, com uma diferença significativa entre eles $(\mathrm{z}=6.5, \mathrm{p}<0.001)$. Valida-se estatisticamente, então, que o reconhecimento do foco é significativamente melhor quando este ocorre sobre um elemento não final do enunciado.

Os únicos contextos que apresentam taxas inferiores a $90 \%$ são o enunciado de foco amplo e aquele cuja localização da palavra focalizada corresponde à cabeça do sintagma entonacional (I), que foram mais comumente confundidos entre si, como pode ser observado na matriz de confusão abaixo.

\footnotetext{
${ }^{5}$ Os efeitos relatados aqui são baseados em Likelihood Ratio Test (LRT).
} 
Tabela 1. Matriz de confusão criada a partir dos resultados do teste perceptivo, em que se apresentam as produções dos enunciados com focalização em diferentes posições (eixo vertical) e a avaliação realizada pelos juízes no teste de percepção (eixo horizontal); na linha diagonal, o número de votos em que a intenção do falante foi bem reconhecida pelos ouvintes.

\begin{tabular}{|c|r|r|r|r|r|r|}
\hline & \multicolumn{7}{|c|}{ Resposta } \\
\hline Tipo de foco & Amplo & \multicolumn{1}{|c|}{$\begin{array}{c}\text { Cabeça } \\
\text { de I }\end{array}$} & \multicolumn{1}{c|}{$\begin{array}{c}\text { Cabeça } \\
\text { de } \boldsymbol{\phi}\end{array}$} & \multicolumn{1}{c|}{$\begin{array}{c}\text { Esqu. } \boldsymbol{\phi} \\
\text { inic }\end{array}$} & $\begin{array}{c}\text { Esqu. } \boldsymbol{\phi} \\
\text { med }\end{array}$ & \multicolumn{1}{c|}{$\begin{array}{c}\text { Esqu. } \boldsymbol{\phi} \\
\text { final }\end{array}$} \\
\hline Amplo & 84 & 8 & 5 & 3 & 0 & 0 \\
\hline Cabeça de I & 20 & 74 & 2 & 3 & 0 & 1 \\
\hline Cabeça de $\boldsymbol{\phi}$ & 1 & 0 & 96 & 3 & 0 & 0 \\
\hline Esqu. $\boldsymbol{\phi}$ inic & 2 & 0 & 3 & 96 & 0 & 0 \\
\hline Esqu. $\boldsymbol{\phi}$ med & 3 & 1 & 2 & 0 & 94 & 0 \\
\hline Esqu. $\boldsymbol{\phi}$ final & 3 & 0 & 1 & 2 & 0 & 95 \\
\hline
\end{tabular}

No entanto, seu reconhecimento é, ainda assim, acima de $60 \%$ em todas as possíveis variações do número de pretônicas. Os índices de reconhecimento do constituinte focalizado, superiores a 60\%, em todos os contextos, e a 90\%, na maioria dos casos, independentemente do número de sílabas pretônicas apresentado, indicam que a marcação prosódica do foco estreito apresenta alta produtividade em interrogativas totais no $\mathrm{PB}$, sendo a palavra fonológica o seu domínio por excelência.

O fato de até mesmo as palavras que não apresentam a condição requerida para a realização do acento secundário (mínimo de duas pretônicas) serem fortemente reconhecidas é um indicativo de que a língua estabelece um sistema de compensação na manifestação das estratégias de focalização. Na subseção seguinte, nossa análise procura definir que estratégias estão atuando na marcação do foco estreito em interrogativas totais nos referidos contextos, observando o número de pretônicas apresentado pelos vocábulos fonológicos para, assim, investigarmos também a participação do acento secundário nesse fenômeno.

\subsection{Análise fonética e fonológica da F0}

\subsubsection{Focalização sobre cabeça do sintagma entonacional (I)}

Quando o vocábulo focalizado ocupa a posição final do enunciado, coincidente com a posição de cabeça do sintagma fonológico (I), podemos dizer que há uma situação potencialmente ambígua, visto que se trata da posição que deverá manifestar também a natureza 
modal do enunciado interrogativo, marcada pelo contorno nuclear. Assim, a ocorrência de uma proeminência sobre esse ponto não seria suficiente para assinalar o foco estreito, como foi apontado em Moraes, Carnaval e Coelho (2015), sendo necessário um correlato especial para diferenciá-lo do foco amplo, como, por exemplo, um pico geminado de tom complexo $\left(\mathrm{HLH}^{*}\right)$, cujo primeiro tom alto está associado à posição do acento secundário sobre pretônica não adjacente à tônica.

De fato, em nosso corpus, nesse contexto, esta modulação característica também foi observada: no foco estreito em cabeça de (I), para palavra com duas ou mais sílabas pretônicas, podemos ressaltar que os dois informantes apresentam o pico geminado, de tom complexo $\mathrm{HLH}^{*}$ em posição nuclear, assinalando sua distinção em relação ao foco amplo. A proeminência inicial, default, é mantida, apresentando aqui uma variação, com o deslocamento do tom alto para a sílaba postônica, $\mathrm{L}+>\mathrm{H}^{*}$, no foco amplo (Figura 6) e $\mathrm{L}+\mathrm{H}^{*}$ no foco estreito (Figura 7).

Figura 6. Forma de onda e curva de F0 suavizada (bandwith $10 \mathrm{~Hz}$ ) do enunciado O primo da Manuela vai derrubar suco de tangerina? pronunciado com foco amplo pelo informante masculino. No quadro à direita, nessa e nas demais figuras, o percentual de reconhecimento correto quanto à localização de foco, obtido pelo enunciado no teste perceptivo.

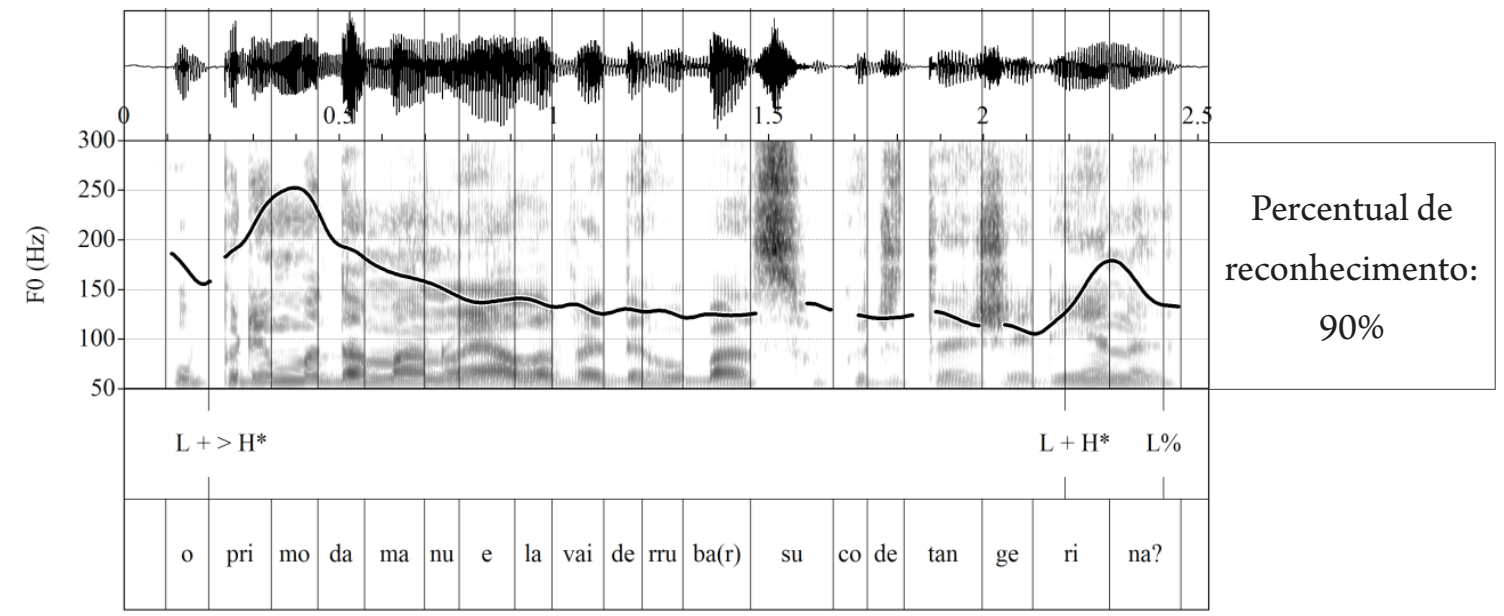

Figura 7. Forma de onda e curva de $\mathrm{F} 0$ suavizada (bandwith $10 \mathrm{~Hz}$ ) do enunciado $\mathrm{O}$ primo da Manuela vai derrubar suco DE TANGERINA? pronunciado com foco sobre DE TANGERINA pelo informante masculino; presença do pico geminado assinalada pelo retângulo em vermelho. 


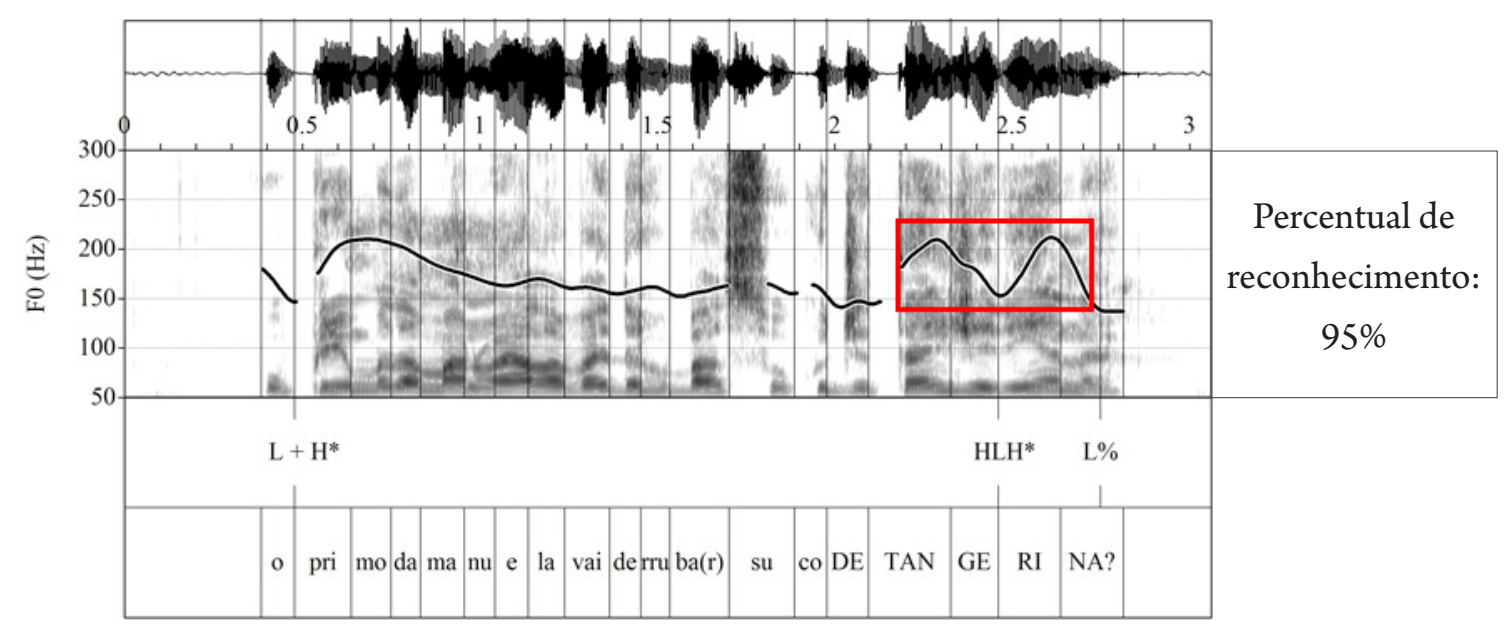

Para averiguar como o foco estreito é assinalado quando a condição canônica de ao menos duas pretônicas para a manifestação do acento secundário não é atendida, analisamos os enunciados em que (i) a palavra focalizada apresenta apenas uma pretônica e (ii) a palavra focalizada não apresenta pretônica.

Em (i), na focalização sobre DE UVA (Figura 9), pode-se observar ainda assim a presença do pico geminado, embora comprimido temporalmente, com uma primeira subida sobre a pretônica (de), seguida de uma ligeira depressão melódica no início da sílaba seguinte, a tônica $[\mathrm{u}]$, para então apresentar seu segundo pico na parte final dessa sílaba, mantendo, assim, o tom complexo $\mathrm{HLH}^{*}$, caracterizando o que se poderia considerar um pico geminado (ou um acento secundário) comprimido, o que se torna evidente quando comparado ao contorno do foco amplo (Figura 8).

Figura 8. Forma de onda e curva de F0 suavizada (bandwith $10 \mathrm{~Hz}$ ) do enunciado $O$ namorado da Luma planejava beber refrigerante de uva? pronunciado com foco amplo pelo informante masculino.

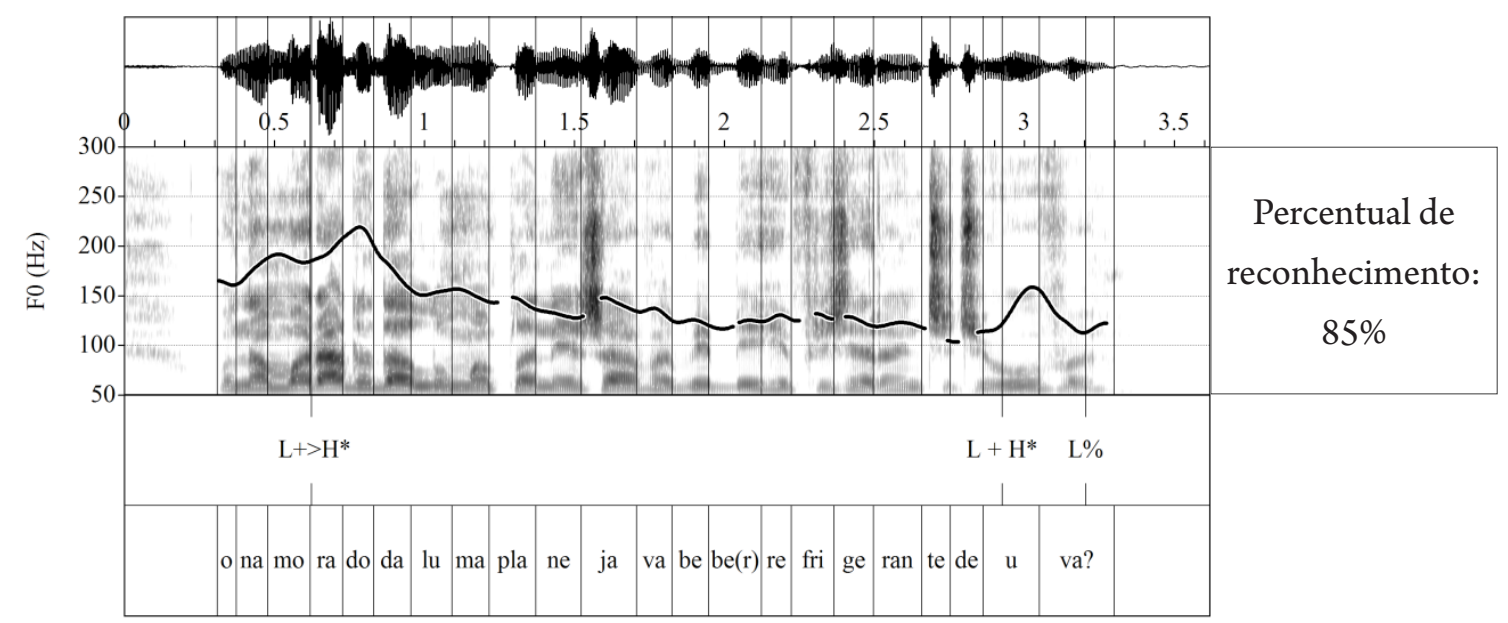


Figura 9. Forma de onda e curva de F0 suavizada (bandwith $10 \mathrm{~Hz}$ ) do enunciado $O$ namorado da Luma planejava beber refrigerante DE UVA? pronunciado com foco sobre DE UVA pelo informante masculino; presença do pico geminado assinalada pelo retângulo em vermelho

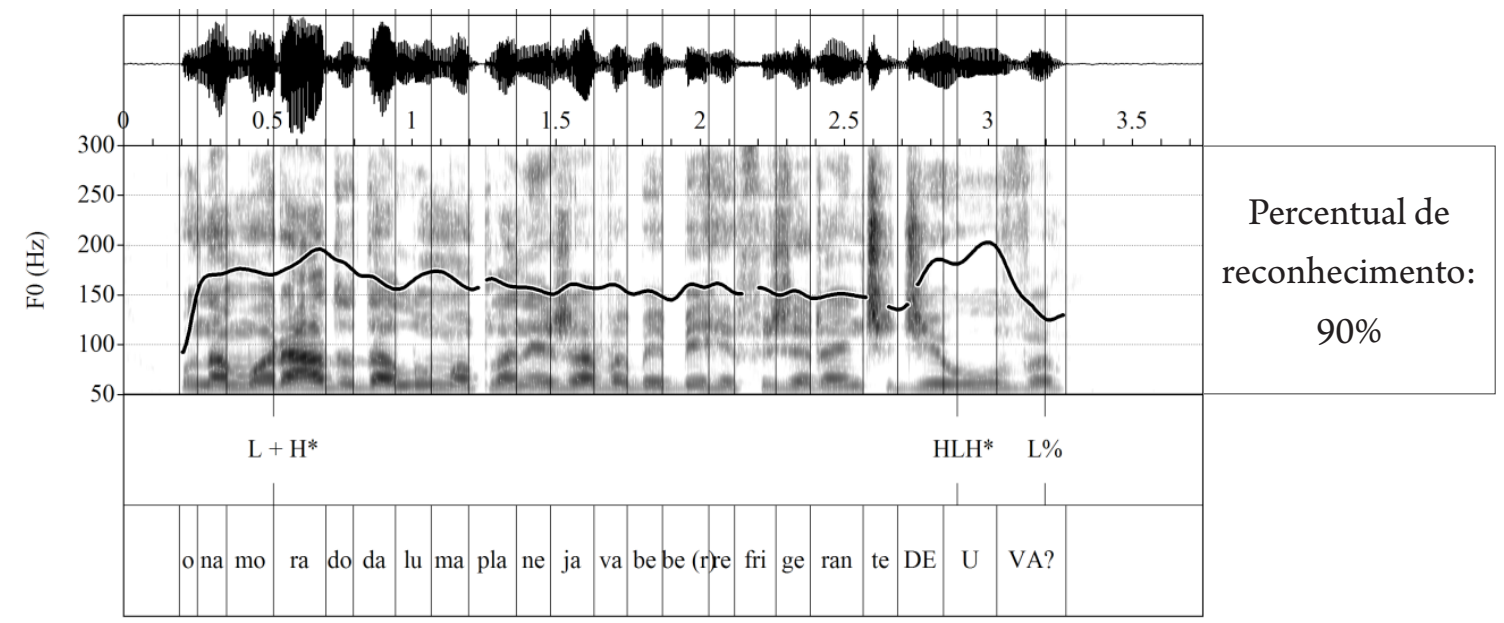

Para o caso (ii), a não existência de pretônica, na focalização sobre QUENTE, fez com que fosse adotada uma outra estratégia: reforço duracional sobre a tônica da palavra em foco e alcance de maior amplitude do pico melódico nuclear, que passa de $172 \mathrm{~Hz}$, no foco amplo (Figura 10), para $286 \mathrm{~Hz}$, no foco estreito em posição nuclear (Figura 11):

Figura 10. Forma de onda e curva de F0 suavizada (bandwith $10 \mathrm{~Hz}$ ) do enunciado Festa cheia costuma dar refresco quente? pronunciado com foco amplo pelo informante masculino.

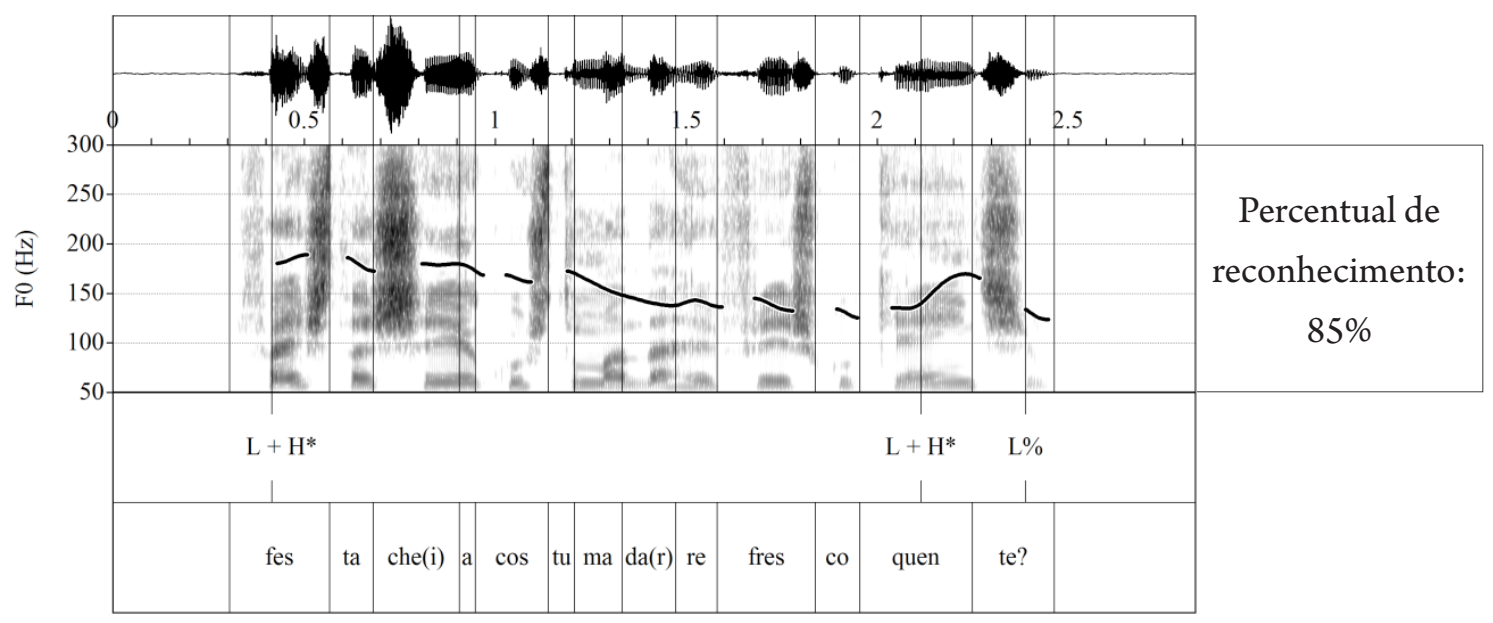


Figura 11. Forma de onda e curva de F0 suavizada (bandwith $10 \mathrm{~Hz}$ ) do enunciado Festa cheia costuma dar refresco QUENTE? pronunciado com foco sobre QUENTE pelo informante em masculino.

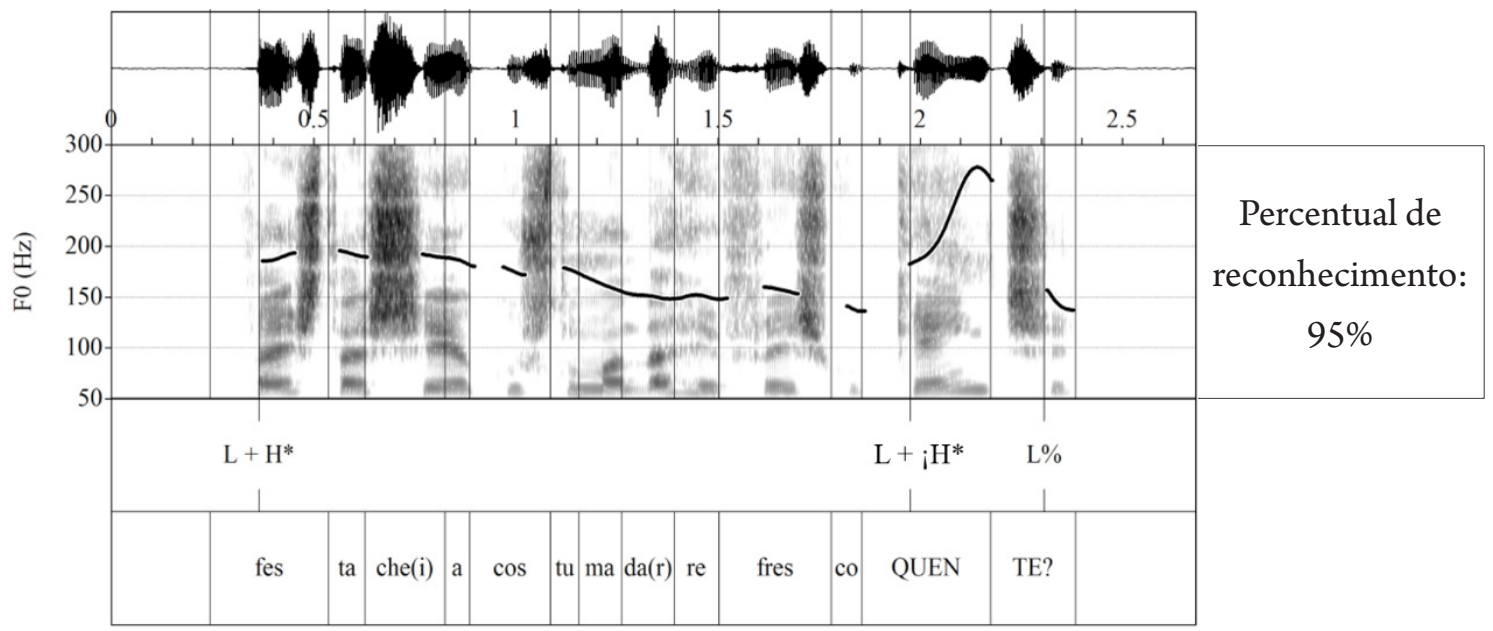

\subsubsection{Focalização sobre cabeça de sintagma fonológico $\phi$}

Nesta subseção, trataremos dos vocábulos focalizados que constituem cabeça de sintagma fonológico $(\phi)$, mas que, diferentemente daqueles analisados anteriormente, não estão na fronteira de sintagma entonacional (I). A estrutura dos enunciados que compõem nosso corpus provê um par de vocábulos fonológicos para cada categoria criada a partir da quantidade de sílabas pretônicas: para vocábulo com duas ou mais sílabas pretônicas, tem-se DA MANUELA e DERRUBAR; para vocábulo com apenas uma sílaba pretônica DA LUMA e BEBER; para vocábulo sem pretônica, CHEIA e DAR.

Com relação às palavras fonológicas $(\omega)$ em posição de cabeça de $\phi$ com duas ou mais pretônicas, caso de DA MANUELA e DERRUBAR, Figuras 12 e 13, respectivamente, podemos observar que a marcação do foco estreito ocorre por uma proeminência geminada sobre o vocábulo sob foco, proeminência essa que se acrescenta às duas proeminências default já mencionadas, a primeira em posição pré-nuclear, a segunda, de natureza modal, em posição nuclear. Soma-se a esta subida suplementar, caracterizada pelo pico geminado assinalado pelo retângulo vermelho nas Figuras 12 e 13, o aumento na duração das sílabas em que os picos melódicos do tom complexo $\mathrm{HLH}^{*}$ estão localizados, ou seja, as sílabas tônica $[$ ' $\varepsilon]$ e segunda pretônica a partir desta $[\mathrm{ma}]$, posição do acento secundário. $\mathrm{O}$ reforço duracional das sílabas, em relação à sua duração em contexto de foco amplo, aliado ao pico geminado são responsáveis pela marcação do foco estreito nestes dois vocábulos. 
Figura 12. Forma de onda e curva de F0 suavizada (bandwith $10 \mathrm{~Hz}$ ) do enunciado O primo DA MANUELA vai derrubar suco de tangerina? pronunciado com foco em DA MANUELA pelo informante masculino; presença do pico geminado assinalada pelo retângulo em vermelho.

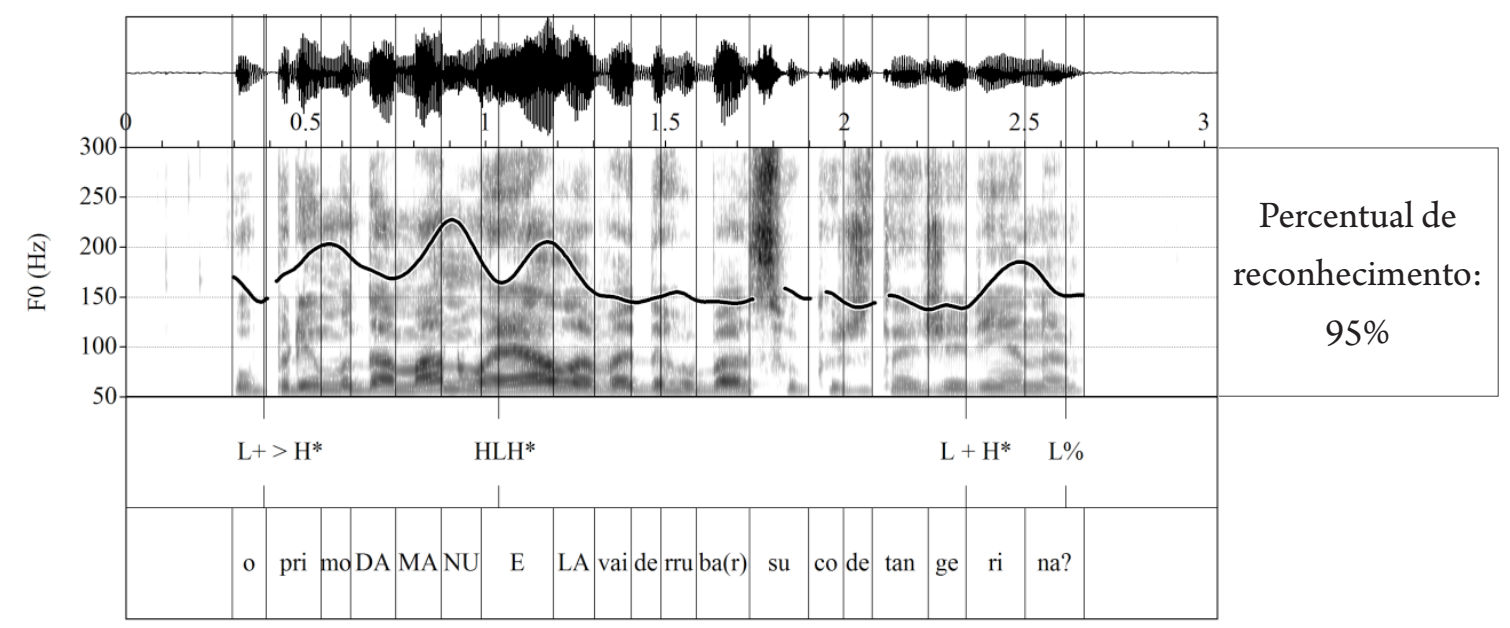

Figura 13. Forma de onda e curva de F0 suavizada $(10 \mathrm{~Hz})$ do enunciado $O$ primo da Manuela vai DERRUBAR suco de tangerina? pronunciado com foco em DERRUBAR pelo informante feminino; presença do pico geminado assinalada pelo retângulo em vermelho.

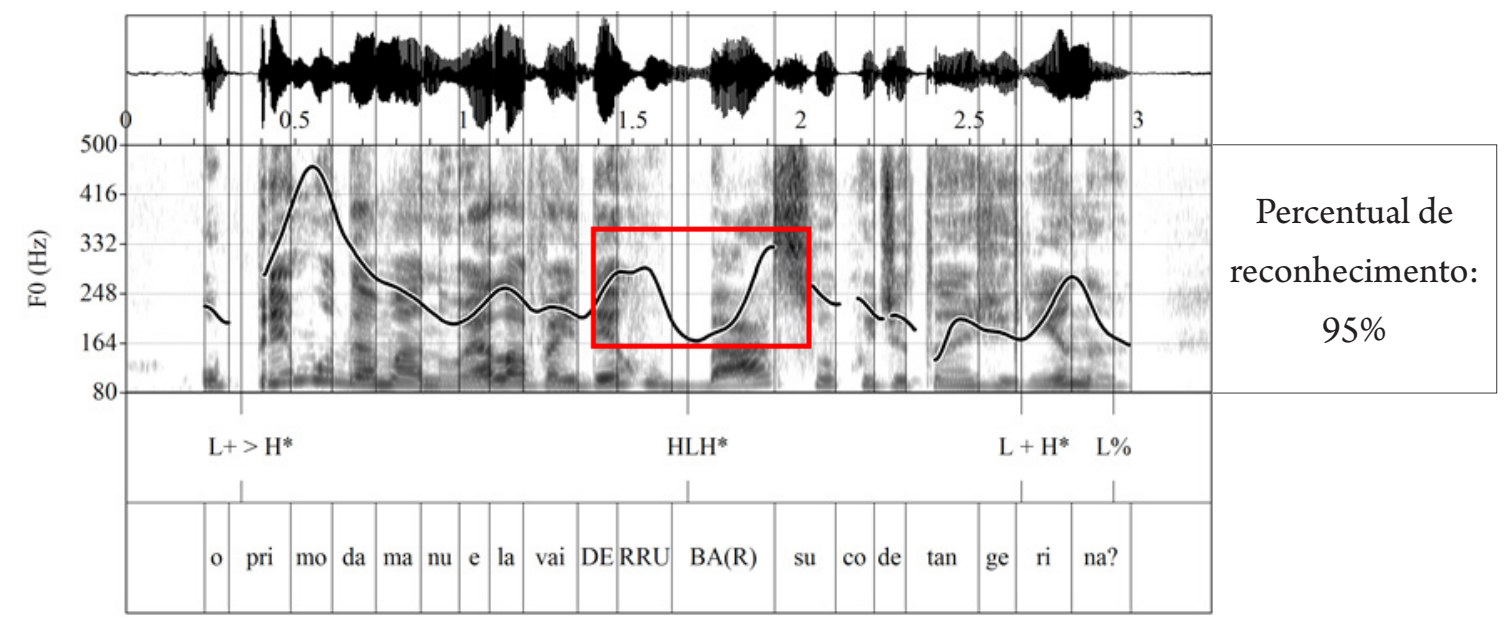

Para as cabeças de $\phi$ com apenas uma sílaba pretônica, DA LUMA e BEBER, ocorrem as mesmas estratégias na marcação do foco, porém, com algumas particularidades: quanto ao pico geminado da subida suplementar, pode ser percebida a presença do tom alto do acento secundário na única pretônica existente, configurando um pico geminado comprimido, mantendo-se o tom $\mathrm{HLH}^{*}$ sobre a palavra fonológica, como descrito na focalização de vocábulo com uma pretônica em cabeça do sintagma entonacional (DE 
UVA); quanto ao aumento da duração, esta estratégia ocorre apenas na sílaba tônica. Os padrões da focalização sobre DA LUMA e BEBER são ilustrados nas Figuras 14 e 15, respectivamente.

Figura 14. Forma de onda e curva de F0 suavizada $(10 \mathrm{~Hz})$ do enunciado $O$ namorado DA LUMA planejava beber refrigerante de uva? pronunciado com foco sobre DA LUMA pelo informante masculino; presença do pico geminado assinalada pelo retângulo em vermelho.

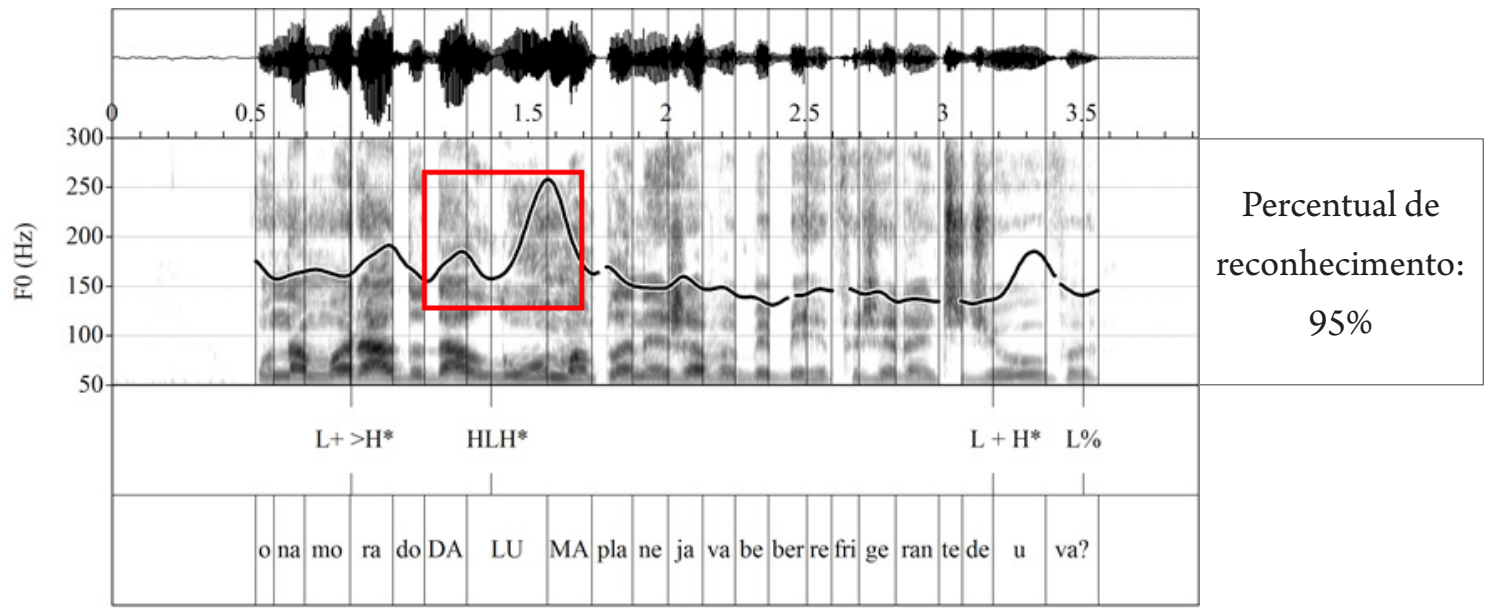

Figura 15. Forma de onda e curva de F0 suavizada $(10 \mathrm{~Hz})$ do enunciado $O$ namorado da Luma planejava BEBER refrigerante de uva? pronunciado com foco sobre BEBER pelo informante feminino; presença do pico geminado assinalada pelo retângulo em vermelho.

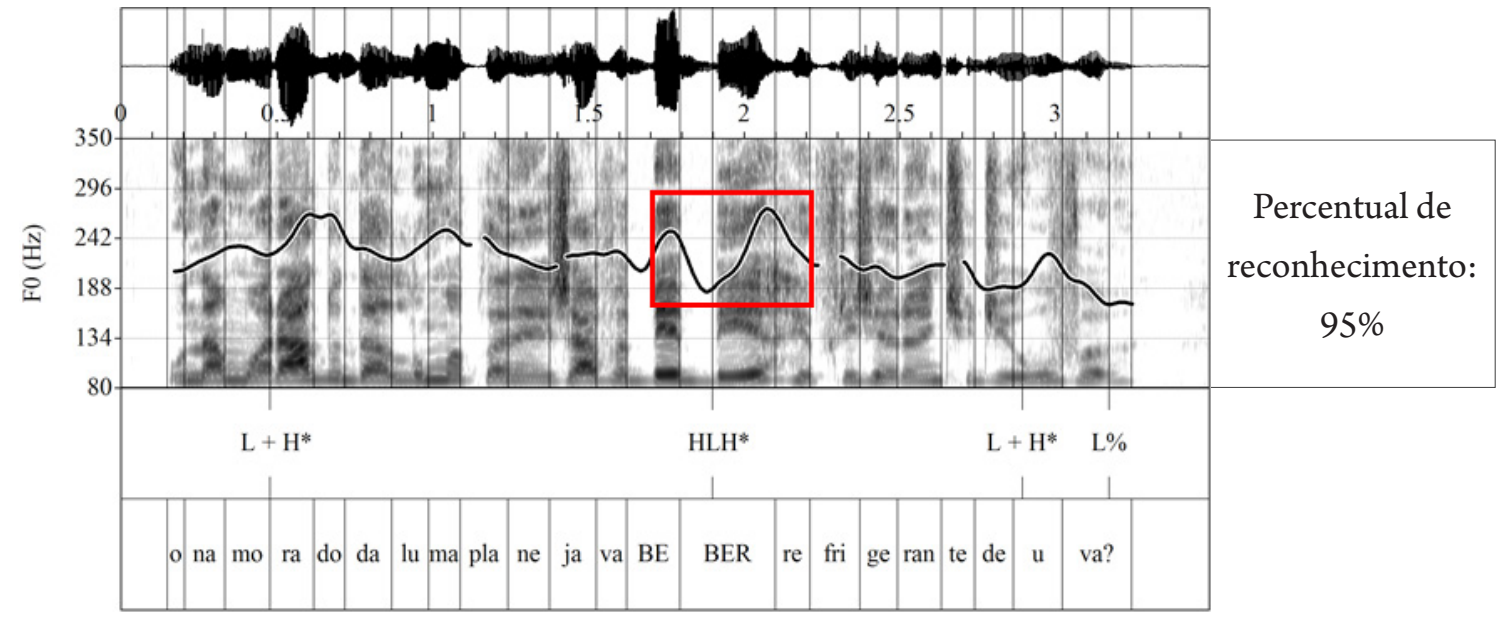

Assim, pode-se afirmar que o pico geminado parece ser um correlato robusto, já que ocorre até mesmo quando o acento secundário é inibido, em palavras com apenas 
uma sílaba pretônica. No entanto, quando a cabeça de $\phi$ não apresenta pretônica, como nos casos de CHEIA e DAR (Figuras 16 e 17, respectivamente), a focalização mantém sua funcionalidade através de um pico suplementar simples e o reforço duracional sobre a tônica da palavra focalizada, apresentando um aumento de $83 \%$ da duração da sílaba tônica, quando comparada à duração da mesma sílaba em foco amplo, isto é, na ausência de foco. Em CHEIA, o informante feminino realizou, ainda, uma quebra temporal, a pausa após o vocábulo focalizado, na fronteira de $\phi$, isolando o constituinte focalizado.

Figura 16. Forma de onda e curva de F0 suavizada $(10 \mathrm{~Hz})$ do enunciado Festa CHEIA costuma dar refresco quente? pronunciado com foco sobre CHEIA pelo informante feminino.

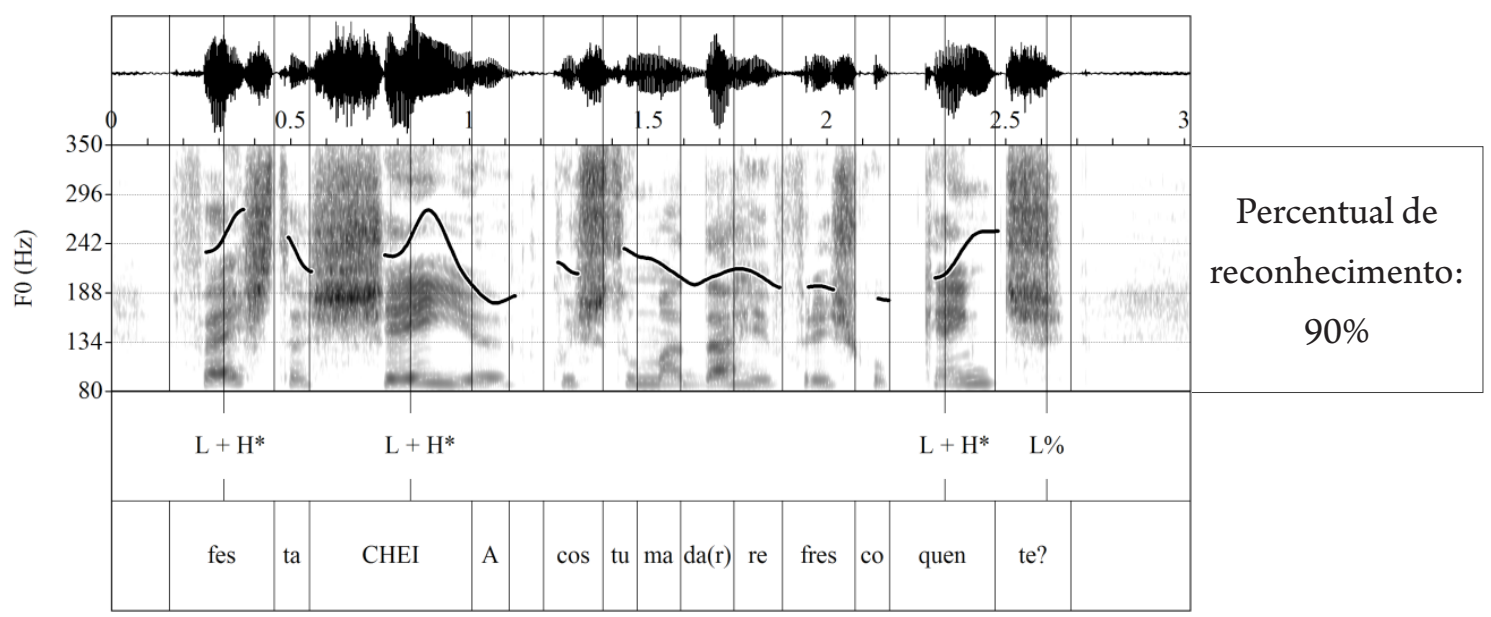

Figura 17. Forma de onda e curva de F0 suavizada $(10 \mathrm{~Hz})$ do enunciado Festa cheia costumaDAR refresco quente? pronunciado com foco sobre DAR pelo informante feminino.

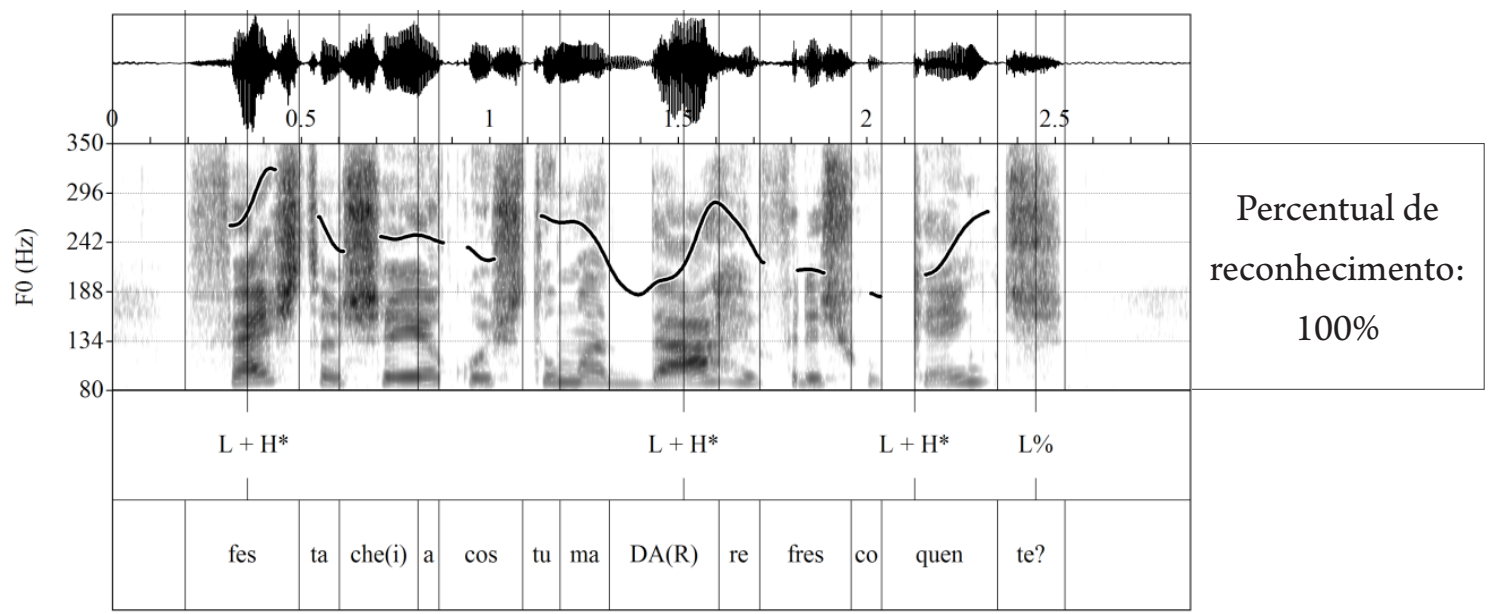




\subsubsection{Focalização sobre vocábulo à esquerda no sintagma fonológico, posição fraca} de $\phi$.

O último contexto de manifestação do foco estreito por nós analisado consiste na posição à esquerda do sintagma fonológico, posição fraca de $\phi$. Para este caso, podemos distinguir três situações prosodicamente distintas, de acordo com a posição que o sintagma fonológico $(\phi)$ que contém a palavra em foco ocupa, dentro da estrutura hierárquica superior, isto é, do sintagma entonacional (I): (i) último $\phi$ de I, em que a posição forte de $\phi$, à direita, apresenta a proeminência modal; (ii) primeiro $\phi$ de I, em que a posição fraca de $\phi$, à esquerda, apresenta uma proeminência default por estar ao início de I; (iii) $\phi$ medial a I (à esquerda do $\phi$ interno ao I). Trataremos, portanto, deste contexto (vocábulo à esquerda de $\phi)$ discriminando essas três possibilidades.

\section{(i) $\Phi$ ao final de I (REFRIGERANTE, REFRESCO e SUCO)}

Quando a palavra focalizada encontra-se em posição fraca, à esquerda, do último $\phi$ de I, observam-se duas estratégias principais, quais sejam, a presença do pico suplementar sobre o foco e o aumento da duração da sílaba tônica da palavra focalizada. Essas duas estratégias são recorrentes em todos os vocábulos, independentemente do número de sílabas pretônicas que apresentam. Em REFRIGERANTE, vocábulo com mais de duas sílabas pretônicas, percebe-se a manifestação do pico geminado no retângulo vermelho sobre a posição do acento secundário na produção do informante feminino (Figura 18). Nos casos de REFRESCO (Figura 18) e SUCO (Figura 19) ocorre um pico suplementar apenas.

Figura 18. Forma de onda e curva de F0 do enunciado O namorado da Luma planejava beber REFRIGERANTE de uva? pronunciado com foco sobre REFRIGERANTE pelo informante feminino; presença do pico geminado assinalada pelo retângulo em vermelho

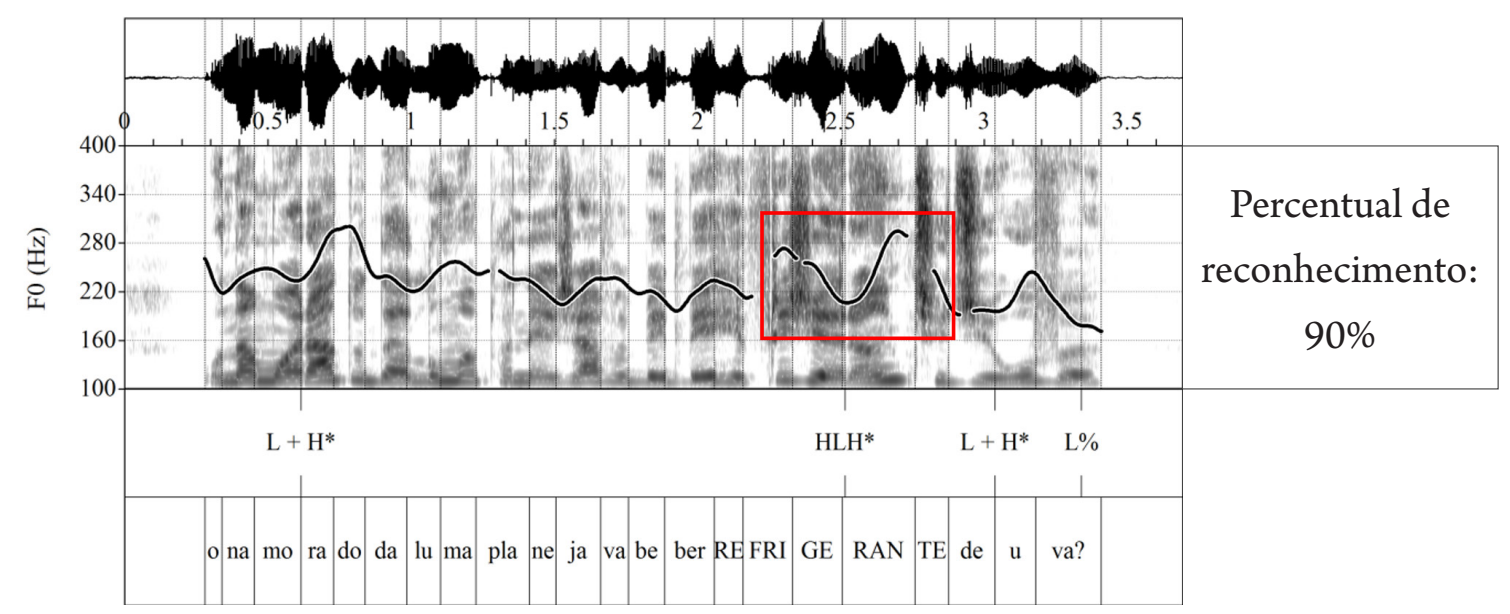


Figura 19. Forma de onda e curva de F0 suavizada $(10 \mathrm{~Hz})$ do enunciado Festa cheia costuma dar REFRESCO quente? pronunciado com foco sobre REFRESCO pelo informante feminino.

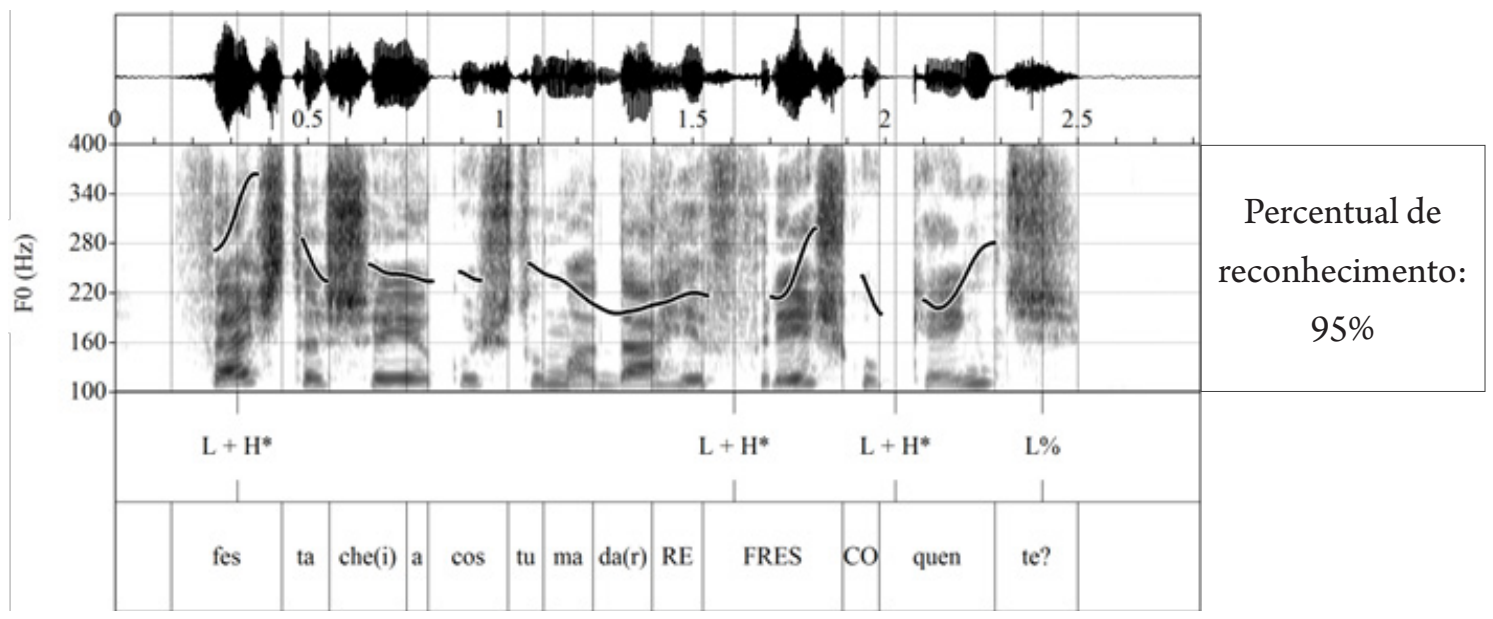

Figura 20. Forma de onda e curva de F0 suavizada $(10 \mathrm{~Hz})$ do enunciado O primo da Manuela vai derrubar SUCO de tangerina? pronunciado com foco sobre SUCO pelo informante feminino.

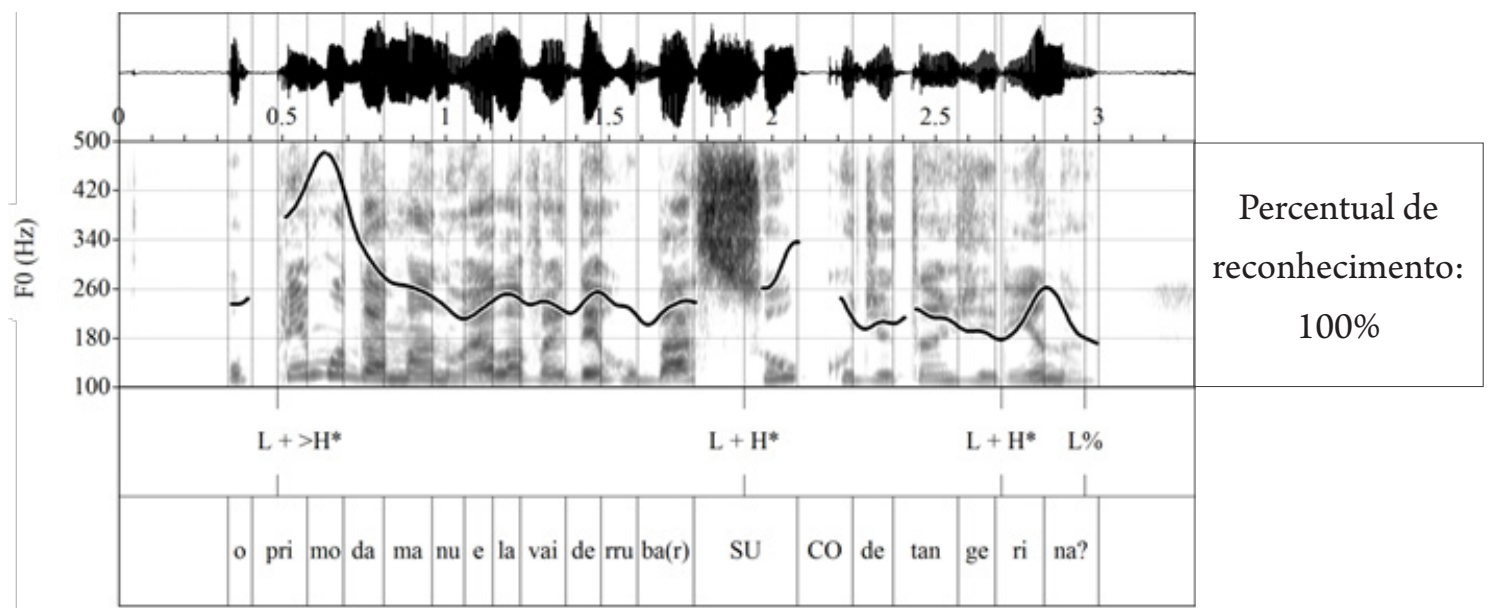

\section{(ii) $\Phi$ ao início de I (O NAMORADO, O PRIMO e FESTA)}

Ao início do sintagma entonacional, isto é, à esquerda de um $\phi$ ramificado, já se espera, como vimos, um movimento ascendente inicial, default, no pré-núcleo, por vezes bastante acentuado, mesmo na ausência de foco sobre esse constituinte (cf. por ex. Figuras 2, 4 e 13). Em vista disso, para a marcação do foco estreito sobre a palavra inicial em posição fraca, uma estratégia complexa entra em jogo. De um lado, temos a presença, além desse pico default sobre a primeira tônica, de um segundo pico, em geral de menor amplitude que o primeiro. Esse segundo pico, que não se confunde com o pico geminado (associado ao acento secundário), incide sobre o vocábulo no final do sintagma fonológico, que ocupa a cabeça 
de $\phi$ (MORAES; CARNAVAL; COELHO, 2015), assinalando assim que há um foco sobre o primeiro $\phi$ do enunciado, e que ele recai sobre seu primeiro vocábulo (pico mais proeminente). Além disso, observa-se um alongamento sobre a tônica da palavra focalizada. Essa espécie de eco ou reduplicação do pico melódico (início e final do $\phi$ ) ocorre tanto em palavras fonológicas que respeitam a condição mínima para a ocorrência do acento secundário, como O NAMORADO (Figura 21), quanto nas demais, como O PRIMO (Figura 22) e FESTA (Figura 23), como se pode observar na figuras a seguir. $\mathrm{O}$ mencionado reforço duracional sobre a tônica da palavra focalizada também se faz presente nesses três casos.

Figura 21. Forma de onda e curva de F0 suavizada $(10 \mathrm{~Hz})$ do enunciado O NAMORADO da Luma planejava beber refrigerante de uva? pronunciado com foco sobre O NAMORADO pelo informante masculino; presença do pico geminado assinalada pelo retângulo em vermelho.

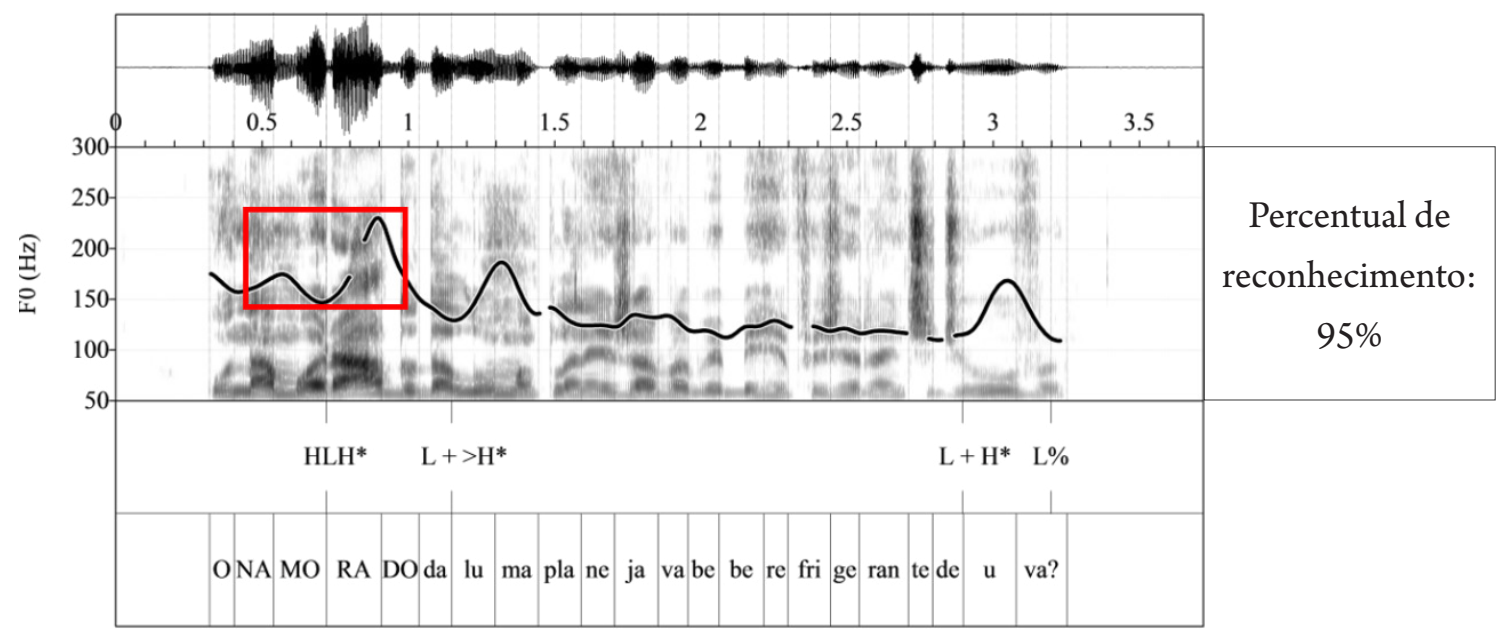

Figura 22. Forma de onda e curva de F0 suavizada $(10 \mathrm{~Hz})$ do enunciado O PRIMO da Manuela vai derrubar suco de tangerina? pronunciado com foco sobre O PRIMO pelo informante masculino.

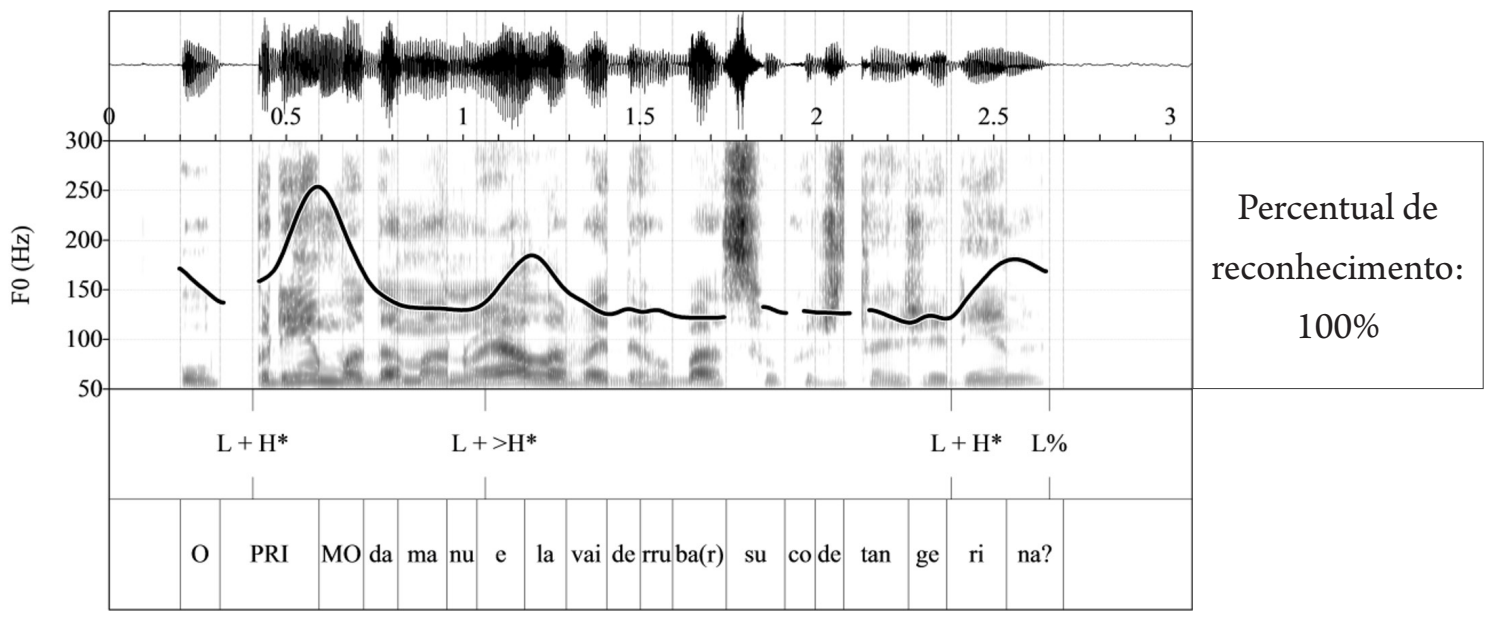


Figura 23. Forma de onda e curva de F0 suavizada $(10 \mathrm{~Hz})$ do enunciado FESTA cheia costuma dar refresco quente? pronunciado com foco sobre FESTA pelo informante masculino.

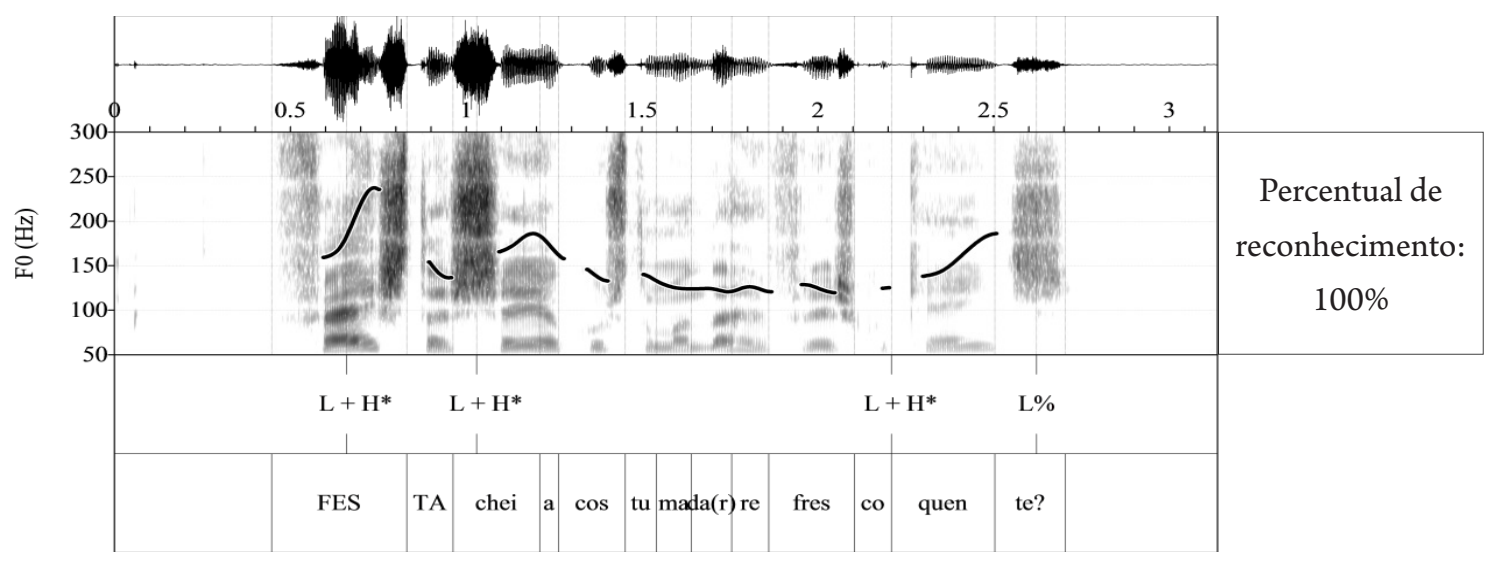

(iii) $\phi$ medial a I (PLANEJAVA, COSTUMA e VAI)

Quando o vocábulo focalizado ocupa a posição fraca do sintagma fonológico $(\phi)$ em posição medial do sintagma entonacional (I), ocorre sobre ele uma subida suplementar às subidas inicial default e final modal. Esta subida suplementar é caracterizada pelo pico geminado em palavra com duas pretônicas (PLANEJAVA - Figura 24), manifestando o acento secundário, e em palavra com apenas uma pretônica (COSTUMA - Figura 25), havendo a compressão do tom melódico complexo $\mathrm{HLH}^{*}$ à estrutura textual do enunciado. Para a palavra sem pretônica (VAI - Figura 26), observa-se um pico simples sobre a palavra focalizada e, ainda, o alongamento significativo da sílaba tônica da palavra focalizada, o que ocorre nos três casos.

Figura 24. Forma de onda e curva de F0 suavizada ( $10 \mathrm{~Hz})$ do enunciado O namorado da Luma PLANEJAVA beber refrigerante de uva? pronunciado com foco sobre PLANEJAVA pelo informante feminino; presença do pico geminado assinalada pelo retângulo em vermelho.

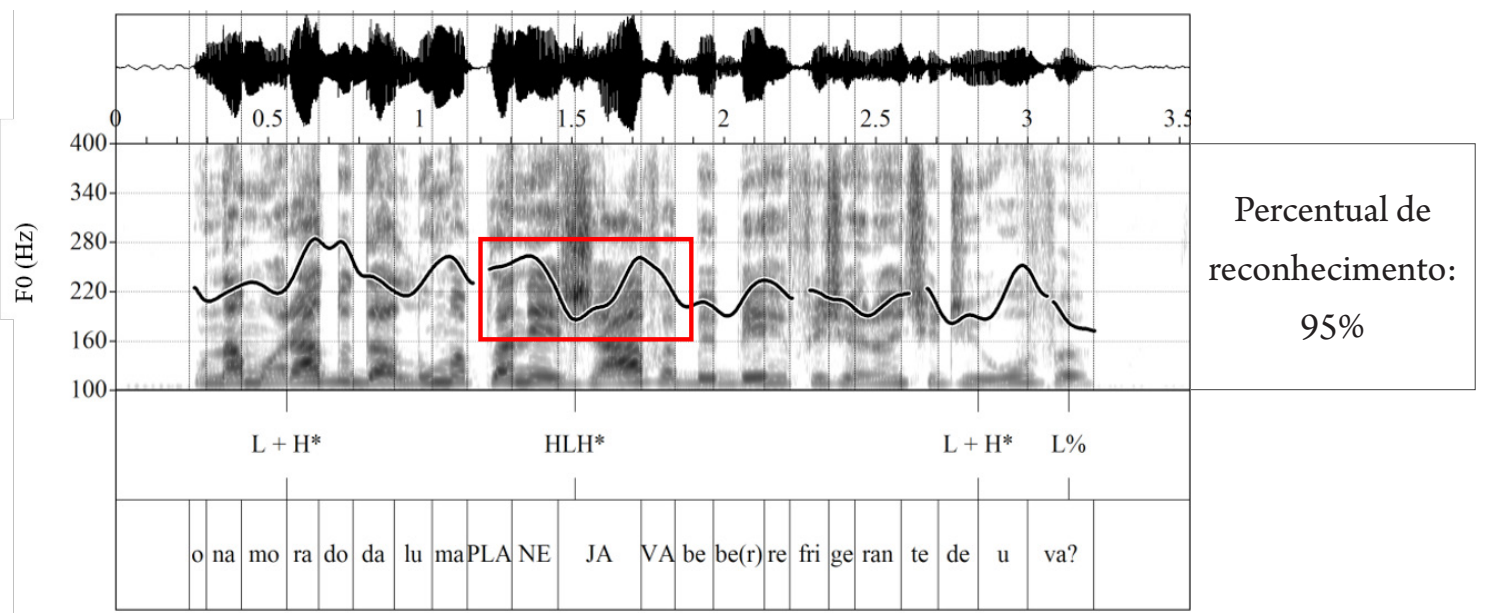


Figura 25. Forma de onda e curva de F0 suavizada $(10 \mathrm{~Hz})$ do enunciado Festa cheia COSTUMA darrefresco quente? pronunciado com foco sobre COSTUMA pelo informante feminino; presença do pico geminado assinalada pelo retângulo em vermelho.

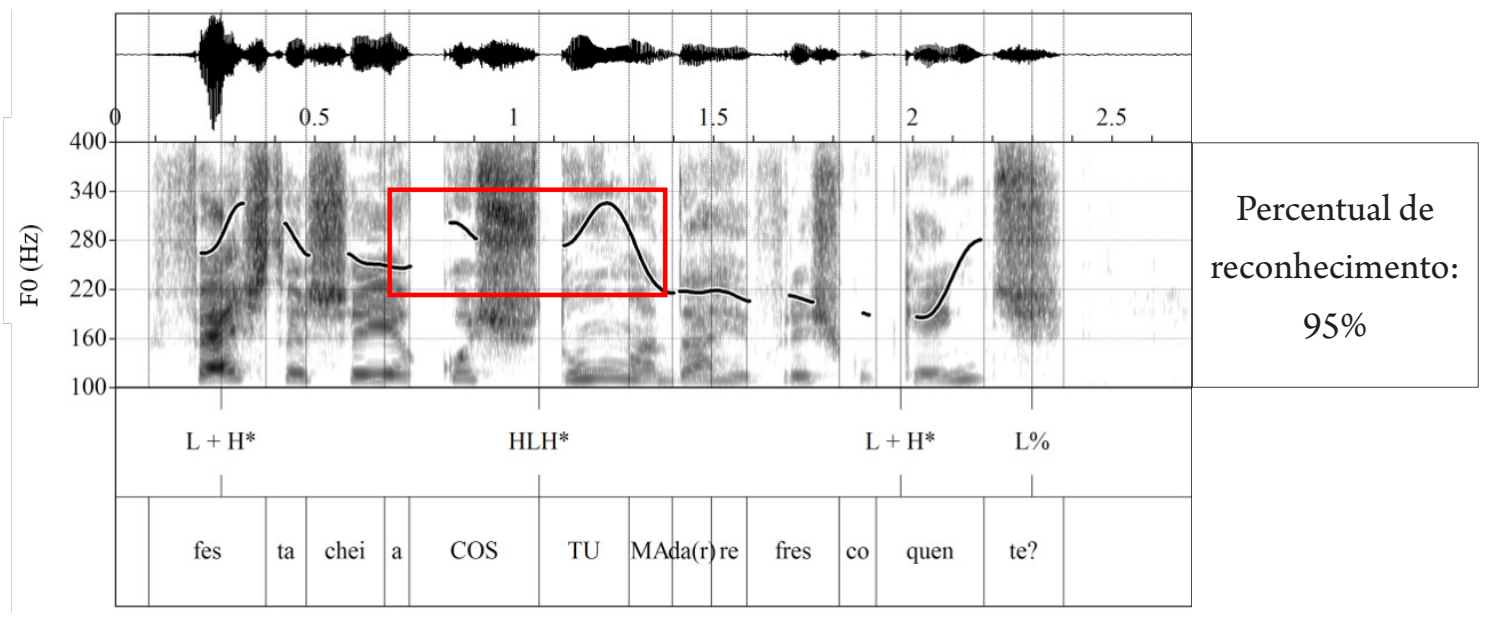

Figura 26. Forma de onda e curva de F0 do enunciado O primo da Manuela VAI derrubar suco de tangerina? pronunciado com foco sobre VAI pelo informante masculino.

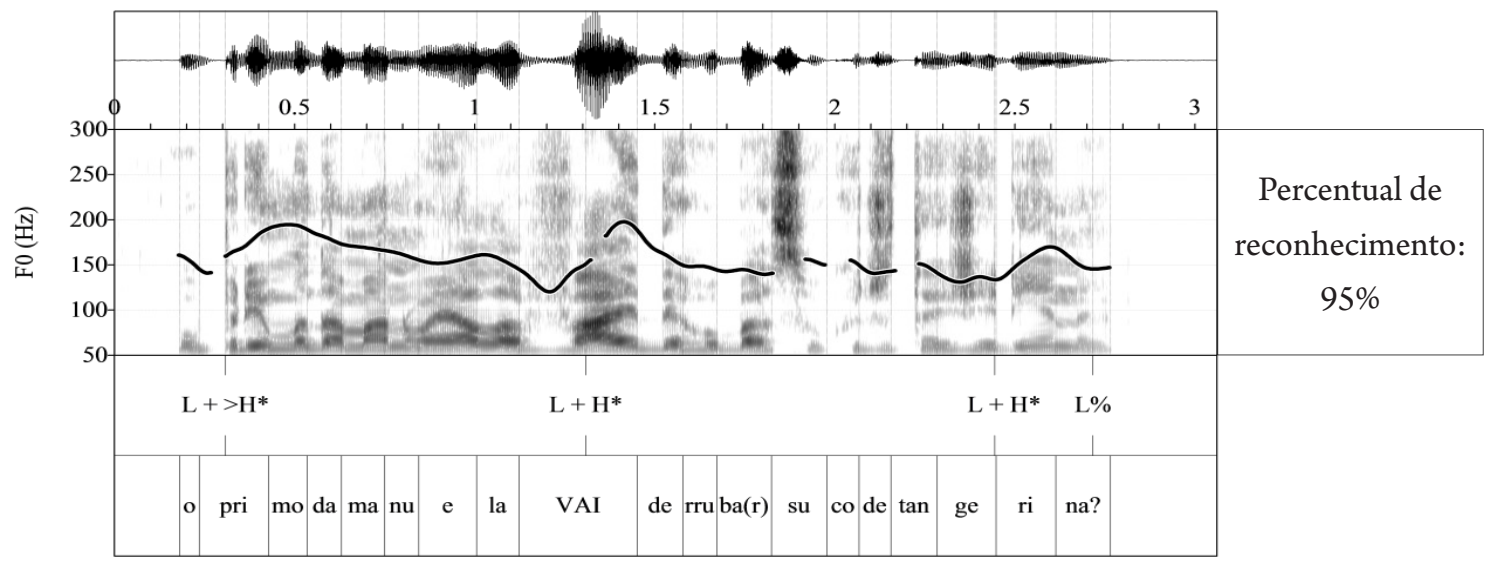

\subsection{Análise da Duração}

(i) Sílabas tônicas

A Figura 27 apresenta a distribuição das medidas de alongamento das sílabas tônicas em função da posição da palavra fonológica que contém a sílaba em questão e da presença ou não do foco estreito sobre essa palavra. Todas as sílabas tônicas dentro das palavras focalizadas apresentam aumento da duração em comparação com a sílaba correspondente no enunciado de foco amplo, com exceção da sílaba tônica da última palavra dos enunciados. As sílabas de palavras não focalizadas não apresentam aumento de duração em comparação com o enunciado de foco amplo. Um "Generalized Linear 
Mixed Model” (GLMM - Modelo Misto Linear Generalizado, usando a função $\operatorname{lme}()$ da livraria $n l m e$ do programa R (PINHEIRO et al., 2018)) foi aplicado sobre as medidas de alongamento da duração das sílabas tônicas, utilizando como fatores fixos a presença ou não do foco sobre a palavra ( 2 níveis) e a posição da palavra dentro da frase (6 níveis), bem como a interação entre eles, e, ainda, como fator aleatório, o falante. O modelo mostrou que a presença do foco tem um efeito significativo $\left(F_{(1,203)}=258, p<0.001\right)$ e explica a maior parte da variância no modelo. A interação entre os dois fatores (presença do foco e posição dentro da frase $)$ também tem um efeito significativo $\left(F_{(5,203)}=7.9, p<0.001\right)$, o que indica que a variação do aumento da duração nas sílabas tônicas ao longo da frase não é uniforme: o maior alongamento em contexto intermediário (posição 3), e menor (isto é, o não alongamento) em contexto final (posição 6) podem justificar esse resultado. De maneira global, a posição da palavra dentro da frase não tem um efeito significativo sobre o alongamento $\left(F_{(5,203)}=2.1, p=0.07\right)$.

Figura 27. Distribuição das medidas de alongamento de sílabas tônicas com (C, em rosa) ou sem foco ( $S$, em azul), em função da posição de sua palavra fonológica dentro da frase ( 1 a 6). Valores em 0 indicam que não houve aumento de duração da sílaba na frase com foco estreito em comparação à frase com foco amplo (ver texto), valores positivos indicam aumento e valores negativos compressão.

\section{Sílaba tônica}

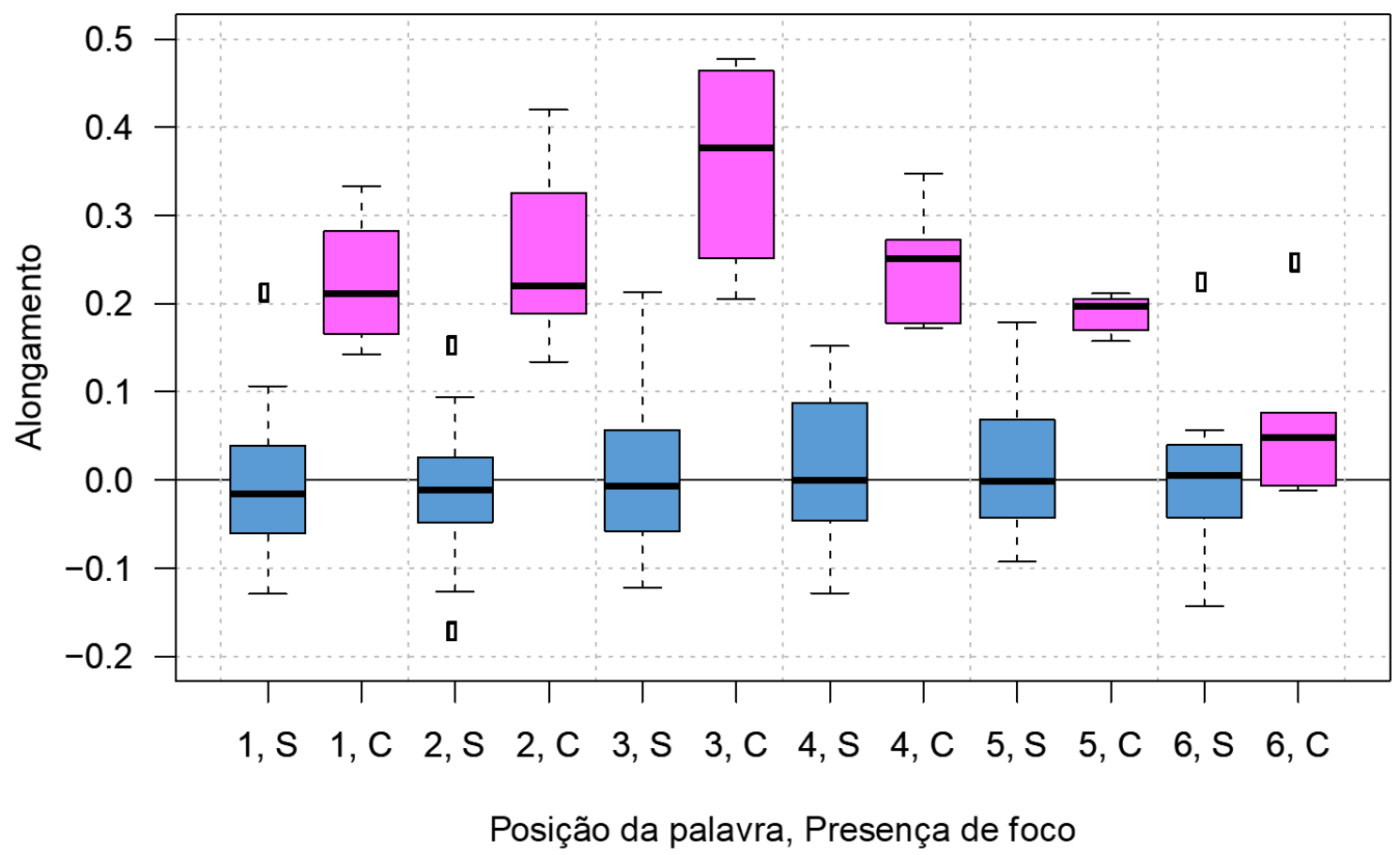




\section{(ii) Sílabas pretônicas}

Medidas similares foram realizadas para as sílabas pretônicas. Um GLMM foi aplicado na medida , composto dos mesmos dois fatores fixos utilizados para as sílabas tônicas (posição da palavra, presença ou não do foco) e mais um fator, descrevendo o tipo de sílaba pretônica (com três níveis: sílaba pretônica com um potencial acento secundário, sílaba pretônica única e as demais sílabas pretônicas que ocorressem). As interações entre esses três fatores foram incluídas dentro do modelo, com o fator Falante como aleatório. O modelo demonstrou que, também para as pretônicas, apenas a presença ou a ausência de foco sobre a sílaba apresenta um efeito significativo sobre o alongamento das sílabas $\left(F_{(1,227)}=71, p<\right.$ 0.001). Os demais fatores e as interações entre eles não atuam significativamente sobre este alongamento, isto é, o aumento de duração não depende significativamente do tipo de sílaba pretônica, apresentando esta um potencial acento secundário ou não.

A Figura 28, à esquerda, apresenta as distribuições das medidas de alongamento por sílabas pretônicas com ou sem foco. $\mathrm{O}$ alongamento médio das sílabas pretônicas em palavras com foco é aproximadamente de $20 \%$ - a ser comparado ao alongamento observado sobre as sílabas tônicas de palavras focalizadas, que se situa em torno de 60\% (média de 0.2 ) em relação às mesmas sílabas com foco amplo.

Figura 28. Distribuição das medidas de alongamento das sílabas pretônicas (à esquerda) e postônicas (à direita), com (em rosa) ou sem foco (em azul). Valores em 0 indicam que não houve aumento de duração da sílaba na frase com foco estreito em comparação à frase com foco amplo (ver texto), valores positivos indicam aumento e valores negativos compressão.

\section{Pretônicas}

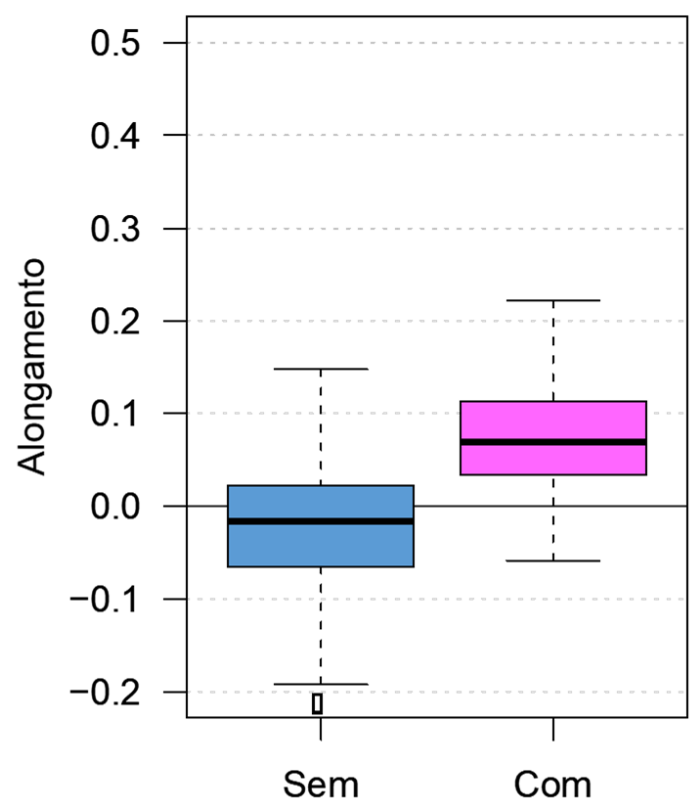

Postônicas

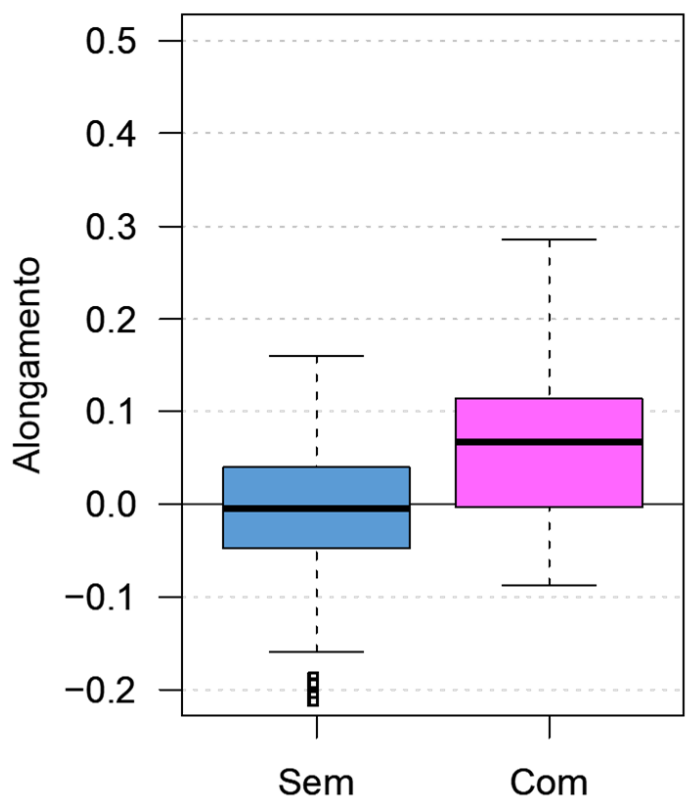




\section{(iii) Sílabas postônicas}

Outro modelo GLMM foi aplicado para as medidas de alongamento observadas nas sílabas postônicas, com dois fatores fixos (presença ou não de foco, posição da palavra - nesse corpus, não há sílabas postônicas de palavras em posição 4, não sendo, portanto, consideradas no modelo) e o fator aleatório, o Falante. Para as postônicas, o modelo também demonstrou que a presença de foco é um fator significativo no alongamento $\left(F_{(1,}\right.$ ${ }_{129)}=22, p<0.001$ ) e este explica a maior parte da variância (ver Figura 28, à direita). A interação significativa $\left(F_{(4,129)}=3.6, p<0.01\right)$ entre a posição da palavra e a presença de foco indica que o alongamento da postônica varia também com a posição dentro da frase, mesmo que seu efeito explique uma parte reduzida da variância. Essa interação é relacionada à ausência de alongamento das sílabas postônicas com foco em posição final dos enunciados

\section{Considerações finais}

Com a aplicação dos testes perceptivos, foi possível conferir o bom reconhecimento dos padrões melódicos da focalização estreita em interrogativas totais no PB, observando os seguintes contextos: vocábulo final do enunciado, coincidindo com cabeça de I; vocábulo cabeça de sintagma fonológico $(\phi)$, posição mais forte; vocábulo que não constitui cabeça de $\phi$, situando-se em posição fraca, à esquerda, podendo o sintagma fonológico estar ao início, meio ou final do enunciado. Ao considerar a atuação do processo nos domínios da palavra fonológica $(\omega)$, baseando-se na quantidade de sílabas pretônicas da palavra focalizada, o presente trabalho procurou averiguar a relevância da manifestação do acento secundário na marcação do foco estreito e quais as estratégias adotadas em sua ausência.

A partir dessa sistematização, foi verificado que o acento secundário no foco interrogativo apresenta como marca formal o pico geminado de tom complexo $\mathrm{HLH}^{*}$ e que este atua na marcação do foco estreito em todos os contextos analisados, quando a condição mínima para manifestação do acento secundário é respeitada (ao menos duas sílabas pretônicas). Quando esta condição não é cumprida, parece ocorrer, de forma recorrente, a compressão do pico geminado em duas sílabas contíguas, em palavras que apresentam apenas uma pretônica, ajustando-se a melodia ao material textual. Portanto, a manifestação melódica do acento secundário na forma de um pico geminado constitui um importante correlato da marcação do foco estreito em interrogativas totais no PB. Esse correlato atuaria em conjunto com o alongamento significativo da sílaba tônica em contextos de 
foco estreito em comparação à duração das mesmas sílabas em contexto de foco amplo, configurando uma estratégia complexa de focalização. Quando o vocábulo em foco não apresenta pretônica alguma e, portanto, não pode manifestar o acento secundário, sequer de forma comprimida, esse aumento da duração parece atuar de modo expressivo para a marcação do foco estreito. No entanto, essa afirmação não se confirma aqui de forma conclusiva, já que, em nosso corpus, há poucas ocorrências de palavras sem sílaba pretônica, o que não torna viável avaliar estatisticamente a significância da diferença entre o alongamento das sílabas tônicas em palavras focalizadas com e sem pretônica ${ }^{6}$.

Em relação ao parâmetro duração, foram considerados dois fatores fixos: a presença ou não de foco e a posição da palavra dentro da frase. Para o primeiro fator, a análise estatística demonstrou, de forma geral, que é significativo o alongamento das sílabas tônicas em palavras focalizadas em comparação a essas mesmas sílabas em contexto sem foco (foco amplo). Foi também constatada uma variação na duração entre sílabas pretônicas com um potencial acento secundário e as demais sílabas pretônicas. No entanto, a significância dessa variação não se comprovou estatisticamente em nosso corpus, devido ao número reduzido de palavras com ocorrência de acento secundário. Portanto, para resultados mais conclusivos em relação à variação de duração da sílaba com acento secundário, é necessária a análise de um corpus mais amplo, construído de modo a viabilizar a análise do efeito potencial do acento secundário sobre a duração em contexto de foco. Em relação à posição da palavra focalizada dentro da frase, foi observada uma variação da duração das sílabas entre as posições do enunciado, que também não pode ser apontada como significativa, devido ao reduzido número de ocorrências em análise.

Vale, por fim, ressaltar que, mesmo em posições prosodicamente fracas, a F0 marca com bastante eficiência o elemento em foco. Isso é especialmente relevante no interior do primeiro sintagma fonológico, onde já há, na posição pré-nuclear, uma proeminência melódica default, e, sobretudo, quando não há espaço para a manifestação do acento secundário. Ainda assim, a distinção entre o foco sobre o primeiro elemento do sintagma $v$ s. o segundo (por ex. "FESTA cheia" vs. "festa CHEIA") e, ainda, sua oposição em relação ao foco amplo é marcada e percebida com sucesso. Nesses três casos, a primeira tônica terá um pico (default); se o foco for amplo, ele será o único pico ao longo do sintagma fonológico, e a F0 deverá ir decaindo ao longo do enunciado, até a tônica final. Se, por outro lado, o foco estreito incidir sobre o primeiro vocábulo do sintagma fonológico, haverá ao

\footnotetext{
${ }^{6}$ Excluídos os casos de clash acentual, foco em "suco", e de palavra ao início do enunciado, "festa”, percebese que as sílabas tônicas de palavras focalizadas sem pretônica apresentam alongamento de $83 \%$, enquanto as sílabas tônicas de palavras focalizadas com pretônica têm o alongamento de $66 \%$.
} 
menos dois picos, um sobre cada uma das tônicas (por ex. em FESta e em CHEia), sendo o primeiro mais acentuado (atingindo um nível mais alto). ${ }^{7}$

\section{Referências}

ARANTES, P. Integrando produção e percepção de proeminências secundárias numa abordagem dinâmica do ritmo da fala. Tese de Doutorado, Universidade Estadual de Campinas, Campinas, 2010.

; BARBOSA, P. A. Acentuação secundária em Português Brasileiro à luz do modelo dinâmico do ritmo: um estudo piloto. Anais do I Congresso Internacional de Fonética e Fonologia / VII Congresso Nacional de Fonética e Fonologia. Belo Horizonte, 2002.

.; . F1 and Spectral Correlates of Secondary Stress in Brazilian Portuguese. In: BARBOSA, P. A.; MADUREIRA, S.; REIS, C. (eds.). Proceedings of the Speech Prosody 2008 Conference. Campinas, Brazil: Editora RG/CNPq, 2008, p. 559-562.

AVESANI, C.; VAYRA, M. Broad, narrow and contrastive focus. In: Florentine Italian. Proceedings of the 15 th ICPhS, Barcelona, 2003.

BARBOSA, P. A. From syntax to acoustic duration: A dynamical model of speech rhythm production. Speech Communication, v. 49, n. 9, p. 725-742, 2007.

BELIÃO, J. How prosody and syntax are mapping: a study of synchronization and congruence. PhD Thesis, Université Paris Ouest Nanterre la Défense, 2016.

BISOL, L. O acento e o pé métrico binário. Cadernos de Estudos Lingüísticos, v. 22, p. 6980, 1992.

. O acento e o pé binário. Letras de Hoje 29 (4), p. 25-36, 1994.

CARNAVAL, M. Foco informacional e foco contrastivo no português do Brasil: uma abordagem prosódica. Dissertação de Mestrado em Letras Vernáculas, Universidade Federal do Rio de Janeiro, Rio de Janeiro, 2017.

COLLISCHONN, G. Um estudo do acento secundário em português. Dissertação de Mestrado, Universidade Federal do Rio Grande do Sul, Porto Alegre, 1993.

. Acento secundário em português. Letras de Hoje 29 (4) p. 43-53, 1994.

DI CRISTO, A. De la microprosodie à l'Intonosyntaxe. Aix-en-Provence: Univerté de Provence, 1985.

FERNANDES-SVARTMAN, F. Acento secundário, atribuição tonal e ênfase em português brasileiro (PB). Estudos Linguísticos, 38 (1), p. 47-58, 2009.

\footnotetext{
${ }^{7}$ Se couber um acento secundário por haver mais de uma pretônica, como em namorado, teremos três picos NAmoRAdo da LUma; o mesmo se aplica quando a segunda palavra é que recebe o foco, como em o PRImo da MAnuEla. Por fim, se o foco estreito estiver sobre o segundo vocábulo do sintagma, haverá igualmente dois picos sobre as duas tônicas, sendo agora o segundo deles mais proeminente. Além do comportamento melódico diferenciado, observa-se, nesses casos, o alongamento da tônica do vocábulo sob o foco.
} 
; ABAURRE, M. B. M.; GONZÁLEZ-LÓPEZ, V. A.; BIANCHI, M.C.C. Secondary stress, intensity and fundamental frequency in Brazilian Portuguese. Journal of Portuguese Linguistics, v. 11, n. 2, 51-67, 2012.

FROTA, S. Prosody and focus in European Portuguese. Phonological phrasing and intonation. New York: Garland Publishing, 2000.

.; CASTELO,J.; CRUZ, M.; BARROS, N.; CRESPO-SENDRA, V.; SILVESTRE, A. P. Melodia ou texto? Estratégias de acomodação entre melodia e texto no Português. In.: Revista Diadorim, v. 17, p. 12-33, 2015.

HAAN, J. Speaking of Questions. An exploration of Dutch question intonation. Utrecht: LOT, 2002.

JUN, S. (Ed.) Prosodic Typology: The Phonology of Intonation and Phrasing. Oxford: Oxford University Press, 2005.

. (Ed.) Prosodic Typology II: The Phonology of Intonation and Phrasing. Oxford: Oxford University Press, 2014.

KRUIJFF-KORBAYOVÁ, I.; STEEDMAN, M. Discourse and information structure. Journal of Logic, Language and Information, v. 12, n. 3, p. 249-259, 2003.

LADD, D. R. Intonational Phonology. Cambridge: CUP, second edition, 2008.

LEE, S. Acento secundário do PB. Letras de Hoje, v. 37, n. 1, p. 149-162, 2002.

MITTMAN, M. O C-ORAL-BRASIL e o estudo da fala informal: um novo olhar sobre o Tópico no Português Brasileiro. Tese de Doutorado em Linguística, Faculdade de Letras, UFMG, 2012.

NESPOR, M.; VOGEL, I.. Prosodic Phonology. Dordrecht: Foris, 1986.

MORAES, J., 2003a. A manifestação fonética do pé métrico, Letras de Hoje 134, dez. 2003, p. 147-162.

2003b. Secondary stress in Brazilian Portuguese: perceptual and acoustical evidence. In: Proceedings of the XV International Congress of Phonetic Science [Barcelona 3-9 August 2003], Glenelg North, Australia: Casual, 2003, p. 2063-2066.

. Variações em torno de tema e rema. Cadernos do CNLF [ IX Congresso Nacional de Lingüística e Filologia] v. IX, n. 17, 2006, p. 279-289.

., CARNAVAl, M.; COElHO, A. A manifestação prosódica do foco em interrogativas totais no Português do Brasil e sua percepção. Revista Virtual de Estudos da Linguagem - ReVEL, v. 13, n. 10, p. 170-194, nov. 2015.

PINHEIRO J.; BATES D.; DEBROY S.; SARKAR, D. and R Core Team. nlme: Linear and Nonlinear Mixed Effects Models. R package version 3.1-137, https: / CRAN.R-project. org/package $=$ nlme. 2018 .

ROSSI, A. Qual é a natureza do acento secundário no português brasileiro? Cadernos Centro Universitário São Camilo, v. 4, n. 1, p. 77-92, 1998. 
SANDALO, M.; F.; ABAURRE, M. B. M.; MANDEL, A.; GALVES, C. M. C. Secondary stress in two varieties of Portuguese and the Sotaq optimality based computer program. Probus, v. 18. n. 1, p. 97-125, 2006.

SITYAEV, D.; HOUSE, J. Phonetic and phonological correlates of broad, narrow and contrastive focus in English. Proceedings of the 15th ICPhS, Barcelona, 2003.

VALLDUVÍ, E. The Informational Component. New York : Garland, 1992.

Information packaging: a survey. Report prepared for WOPIS (Word Order, Prosody, and Information Structure). University of Edinburgh, 2003.

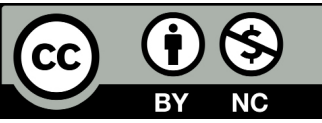

Data de submissão: $15 / 03 / 2018$

Data de aceite: $21 / 11 / 2018$ 